Kouamenan, Djro Bilestone Roméo : Du rituel du consensus au processus de prise de décision. L'élection du pâpe et du Roi des Romains au Moyen Âge, in: Regards croisés Afrique-Europe 1 (2021), p. 17-57

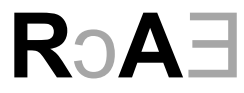

University of Bamberg Press - ISSN : 2749-8514

DOI: https://doi.org/10.20377/rcae-12

(finalisé: 30/11/2021 - publié: 15/12/2021)

\author{
DJRO BiLESTONE ROMÉo KOUAMENAN
}

\title{
Du rituel du consensus au processus de prise de décision
}

\section{L'élection du pâpe et du Roi des Romains au Moyen Âge}

\section{Résumé}

En Europe occidental, la dignité royale était légitimée par la consanguinité. L’Empire et l'Église considéraient, en revanche, que le libre choix était plus important que la coïncidence biologique de l'ascendance. L'élection à la majorité des voix devenait la norme dans l'Église entre le $\mathrm{XII}^{\mathrm{e}}$ et le XIII ${ }^{\mathrm{e}}$ siècle. Cependant, au cours du XIII ${ }^{\mathrm{e}}$ siècle, la nécessité apparut d'harmoniser l'idée séculière de l'élection, comprise comme un rituel du consensus, avec l'idée canonique des critères de l'élection libre, telles qu'elles ont été développées pendant la Querelle des investitures et la réforme de l'Église depuis le $\mathrm{XI}^{\mathrm{e}}$ siècle.

Mots clés : acclamation, consensus, élection, Empire, papauté

\section{Zusammenfassung}

In Westeuropa wurde die Königswürde durch Abstammung legitimiert. Im Reich und in der Kirche galt dagegen die freie Wahl als wichtiger als der biologische Zufall der Abstammung. Die Wahl mit der Mehrheit der Stimmen wurde in der Kirche zwischen dem 12. und dem 13. Jahrhundert zur Norm. Im Laufe des 13. Jahrhunderts entstand jedoch die Notwendigkeit, die weltliche Vorstellung von der Wahl als Konsensritual mit den aus dem kanonischen Recht stammenden Kriterien für eine freie Wahl zu harmonisieren, wie sie während des Investiturstreits und der Kirchenreform im 11. Jahrhundert entwickelt worden waren.

Schlagwörter: Akklamation, Konsens, Wahl, Reich, Papsttum

catégorie: article original 


\begin{abstract}
In Western Europe, royal dignity was legitimized by consanguinity. But the Empire and the Church considered free choice to be more important than the biological coincidence of extraction. Election by a majority of votes became the norm in the Church between the twelfth and thirteenth centuries. However, during the thirteenth century, the need arose to harmonize the secular idea of election (understood as a ritual of consensus) with the canonical idea of the criteria of free election (as developed during the Investiture Controversy and the Church Reformation since the eleventh century).
\end{abstract}

Key words: acclamation, consensus, election, Empire, papacy

\title{
Contact
}

contact de l'auteur/Autorkontakt/author contact : bilestonekouamenan@uao.edu.ci contact de la revue/e-mail Zeitschrift/journal contact : redaktion.rcae@uni-bamberg.de journal homepage : https://ubp.uni-bamberg.de/rcae/index.php/rcae

Djro Bilestone Roméo Kouamenan est assistant d'histoire médiévale à l'Université Alassane Ouattara de Bouaké (Côte d'Ivoire). Sa thèse sur les favoris aux cours royales de l'Angleterre et de la France au XIV et $\mathrm{XV}^{\mathrm{e}}$ siècle a été couronnée du prix Hans Löwel de l'Université de Bamberg et paraîtra bientôt dans la série "Pariser Historische Studien" de l'Institut historique allemand de Paris.

Djro Bilestone Roméo Kouamenan ist Assistent für Mittelalterliche Geschichte an der Université Alassane Ouattara in Bouaké (Côte d'Ivoire/Elfenbeinküste). Seine Dissertation über Favoriten am englischen und französischen Königshof im Spätmittelalter wurde mit dem Hans Löwel Preis der Universität Bamberg ausgezeichnet und in die Reihe „Pariser Historische Studien“ des Deutschen Historischen Instituts Paris aufgenommen.

Djro Bilestone Roméo Kouamenan is junior lecturer of medieval history at the Université Alassane Ouattara in Bouaké (Côte d'Ivoire/Ivory Coast). His thesis on favourites at the English and French royal courts in the later Middle Ages was awarded the Hans Löwel Prize of the University of Bamberg and included in the series "Paris Historical Studies" of the German Historical Institute Paris. 


\section{Introduction}

Parler de l'élection au Moyen Âge peut surprendre, puisque la forme de gouvernement connue est celle monarchique consolidée par le principe dynastique, légitimée par le sacre et appuyée sur l'Église. Pourtant, la succession ne fut qu'une des formes de la pratique, l'élection étant une forme tout aussi légitime et courante, particulièrement privilégiée par le Saint-Empire romain germanique où la monarchie héréditaire ne prévalait pas. ${ }^{1}$ Elle était étroitement liée à la notion de représentation politique déjà présente dans le vocabulaire politique à partir de la fin du XIII $^{\mathrm{e}}$ siècle. ${ }^{2}$

Dans la seconde moitié du $\mathrm{XX}^{\mathrm{e}}$ siècle, des travaux de science politique $^{3}$ ont, cependant, nié au Moyen Âge toute représentation politique avant l'invention $\mathrm{du}$ gouvernement représentatif au $\mathrm{XVIII}^{\mathrm{e}}$ siècle. Ce faisant, cette approche ne fait pas qu'ignorer le contexte socio-historique et la culture politique des groupes ecclésiastiques et

\footnotetext{
${ }^{1}$ Les historiens modernes ont considéré qu'il s'agissait d'un déficit dans la constitution politique de l'Empire, qui avait contribué de manière décisive à l'affaiblissement de la royauté et à la fragmentation territoriale de l'Allemagne: Andreas BÜTTNER : Königsherrschaft im Mittelalter (Seminar Geschichte), Berlin/Boston 2018; Jörg RoGGE : Die deutschen Könige im Mittelalter. Wahl und Krönung (Geschichte kompakt), Darmstadt 2006; Wahlen und Wählen im Mittelalter (Vorträge und Forschungen 37), Reinhard SCHNEIDER/Harald ZimmermanN, Sigmaringen 1990. La perception médiévale, cependant, était tout autre. Au XII ${ }^{\mathrm{e}}$ siècle, l'évêque et chroniqueur allemand Otton de Freising a clairement formulé l'importance de la monarchie élective dans sa description de l'élection du roi Friedrich Barberousse en 1152: «car ce droit », écrit-il, «à savoir que la dignité royale n'est pas héritée selon la consanguinité, mais que les rois sont nommés par élection des princes, est revendiqué par l'Empire romain comme son privilège spécial » (nam id iuris Romani imperii apex, videlicet non per sanguinis propaginem descendere, sed per principum electionem reges creare, sibi tamquam ex singulari vendicat prerogativa), OTTON DE FREISING : Ottonis et Rahewini gesta Friderici I. imperatoris, Hanovre 1912, p. 103.

${ }^{2}$ Adalbert PoDLECH : Repräsentation, in: Geschichtliche Grundbegriffe. Historisches Lexikon zur politisch-sozialen Sprache in Deutschland, éd. O. Brunner/W. Conze/R. Koselleck, Stuttgart 1972, vol. 5, p. 509-547. On trouvera la traduction française sous le titre La représentation. Une histoire du concept, Trivium 16 (2014), https://journals.openedition.org/trivium/4781 . Voir également Hofmann HASsO : Repräsentation. Studien zur Wort- und Begriffsgeschichte von der Antike bis ins 19. Jahrhundert, Berlin 2003.

${ }^{3}$ Bernard MANIN : Principes du gouvernement représentatif, Paris 1995; Hanna FENICHEL : The Concept of Representation, Berkeley 1972.
} 
laïcs concernés, alors que les historiens médiévistes en ont démontré l'importance et l'intérêt dans les sociétés médiévales. ${ }^{4}$ Elle conforte davantage les théories politiques actuelles dans leurs efforts de prêter à l'élection au Moyen Âge un sens généralement inexact, à savoir l'habilitation d'une personne ou d'un groupe de personnes à parler au nom des autres membres de la collectivité, légitimée par le décompte de votes exprimant les volontés individuelles de ces derniers. Il va sans dire que la procédure électorale tout comme l'idée de ce qui était une élection au Moyen Âge ne correspondent pas à ce que l'on peut observer aujourd'hui.

Certes, au contraire de cette approche d'interprétation globale privilégiée en sciences politiques, l'approche historique permet de mettre en évidence que le sens de l'élection, au Moyen Âge, était dicté par des contextes précis. ${ }^{5}$ Mais l'importance du rituel pour établir le consensus dans l'ensemble du processus devant aboutir à la décision de vote ne doit pas être sous-estimée. Ce sont les paroles et les gestes plus ou moins codifiés et ritualisés qui fondent la légitimation du pouvoir, puisqu'il s'agit ici précisément d'une action socialement standardisée et répétitive avec une efficacité performative. ${ }^{6}$ L'idée et la pratique sont

4 The Fifteenth Century, éd. Linda Clark/Christine CARPenter, vol. 4 : Political Culture in Late Medieval Britain, Woodbridge 2004; David L. POTTER : Politics and Faction at the French Court from the Late Middle Ages to the Renaissance. The Development of a Political Culture, http://cour-de-france.fr/article1883.html .

${ }^{5}$ Voir par exemple les travaux de Corinne PÉNÉAU: Pour une histoire des élections médiévales et modernes, Cahiers de recherches médiévales et humanistes 20 (2010), p. 127-133; Élections et pouvoirs politiques du VII ${ }^{\mathrm{e}}$ au XVII ${ }^{\mathrm{e}}$ siècle, éd. Corinne PÉNÉAU Bordeaux 2008.

6 Au sujet du concept de rituel, voir Barbara STOLLBERG-RILINGER: Rituale, Francfort/New York 2013, qui en propose une défintion à la p. 9: «Als Ritual im engeren Sinne wird hier eine menschliche Handlungsabfolge bezeichnet, die durch Standardisierung der äußeren Form, Wiederholung, Aufführungscharakter, Performativität und Symbolizität gekennzeichnet ist und eine elementare sozial strukturbildende Wirkung besitzt. Hingegen wird von Ritualisierung im weiteren Sinne schon dann gesprochen, wenn sich ein bestimmtes Verhalten in seiner äußeren regelmäßig wiederholt». Pour un approfondissement du sujet, cf. les conclusions des travaux du Sonderforschungsbereich (en abrégé SFB = Centre de recherches collaboratives) de Münster sur la communication symbolique (SFB 496 : Symbolische Kommunikation) et de Heidelberg sur la dynamique du rituel (SFB 619: Ritualdynamik), qui ouvrent 
qu'un pouvoir légitime est consenti à travers un processus qui suppose un rite particulier donnant lieu à un usage collectif et performatif de la parole, et dicté par une seule finalité : l'unanimité et le consensus sur la personne choisie.

La question examinée ici est donc de savoir ce qu'implique le verbe élire, au Moyen Âge, et qui avait le droit de voter ? Quelles significations l'élection avait-elle pour les acteurs ? Se manifestait-elle par un simple choix, comme l'indique le sens premier du mot, electio, ou s'agissait-il d'une véritable élection ? En fonction de quelles conceptions de la communauté et de la politique la royauté élective et celle héréditaire étaient-elles en concurrence ?

Cet article montre qu'on ne peut trancher radicalement entre l'élection et la succession héréditaire. Au contraire, ces deux formes de dévolution du pouvoir coexistaient et s'articulaient, de sorte que, sur la base de chroniques, ${ }^{7}$ de documents pontificaux ${ }^{8}$ et d'un ancien

d'intéressantes perspectives sur la performativité du rituel, de même quant au rôle joué par le symbolisme dans la construction de l'ordre social : Alles nur symbolisch? Bilanz und Perspektiven der Erforschung symbolischer Kommunikation, éd. Barbara STOLLBERGRilinger/Tim NeU/Christina BrAUnER, Cologne 2013; Ritual und Ritualdynamik. Schlüsselbegriffe, Theorien, Diskussionen, éd. Christiane BRosiUs/Axel MiCHAELS/Paula SCHRODE, Göttingen 2013.

7 The First Crusade. The Chronicle of Fulcher of Chartres and Other Source Materials, éd. Edward M. Peters, Philadelphia 1998; The Chronicles of Rome. An Edition of the Middle English Chronicle of Popes and Emperors and The Lollard Chronicle, éd. Dan Embree, Woodbridge 1999; The First Crusade, The Accounts of Eye-Witnesses and Participants, éd. August C. Krey, Princeton 1921; ORDERIC VITALIS : The Ecclesiastical History of Orderic Vitalis, vol. 6, contenant les livres 11, 12 et 13, éd. et trad. Marjorie Chibnall, Oxford 1978; MARTIN DE TROPPAU : Chronicon Pontificum et Imperatorum, in : MGH SS 22, Hanovre 1856, p. 377-475 (Monumenta Germaniae Historica sera cité MGH); Narratio de electione Lotharii, in : MGH SS 12, Hanovre 1856, p. 509-512.

${ }^{8}$ La bulle papale Ubi periculum de Grégoire X en 1274, disposition : < Della elezione e della potestà dell'eletto >, http://www.intratext.com/IXT/ITA0136/_P5.HTM; la lettre pontificale dite Deliberatio Domini Papae super facto Imperii de Tribus Electis, in : Regestum Innocentii III papae super negotio Romani imperii, éd. Friedrich Kempf (Miscellanea Historiae Pontificiae), Rome 1947, vol. 12, p. 75-91, dans laquelle le pape Innocent III réaffirme la royauté élective au détriment de celle héréditaire. Il y soutient que la transition père-fils, ou frère-frère, est une menace bien plus grande pour la liberté de l'Empire et de ses princes. Ce document est présenté et entièrement traduit par Claude Joseph DE 
coutumier allemand datant du XIII ${ }^{\mathrm{e}}$ siècle ${ }^{9}$ l'analyse des logiques sociales qui sous-tendent l'élection au Moyen Âge sera faite. Tout en questionnant les conceptions idéelles en fonction desquelles elle prend sens, l'intérêt sera aussi porté sur le processus par lequel la règle majoritaire vient à s'imposer, de même que sur les évolutions chronologiques les plus significatives. L'étude examinera les conceptions légitimantes de la représentation et de dévolution du pouvoir, mobilisées par l'élection et l'hérédité. Elle mettra également l'accent sur les élections royales des $\mathrm{XI}^{\mathrm{e}}$ et $\mathrm{XII}^{\mathrm{e}}$ siècles de sorte à montrer qu'elles n'étaient rien d'autre qu'un rituel d'expression du consensus avec le souverain à choisir. D'où l'inutilité d'une délimitation de l'électorat. Elle planchera, en dernier ressort, sur les procédures et les pratiques de l'élection dans l'institution ecclésiastique ainsi que leur introduction et adaptation dans l'Empire.

\section{La légitimation par l'origine ou par le choix ?}

Pour répondre à cette question, il convient de s'interroger sur le potentiel de légitimité de l'élection, par rapport au droit successoral, au regard des conceptions médiévales de la représentation. Elles mettent en concurrence l'élection avec le principe dynastique.

\subsection{Le potentiel de légitimité de l'élection}

Tout au long du Moyen Âge, et au-dela, le pouvoir séculier comme le pouvoir écclésiastique étaient perçues comme émanant de la volonté de Dieu. Ainsi, l'installation et la légitimité de l'empereur et du roi comme celles du pape, des évêques et des abbés restaient fondées sur l'approbation divine. Celle-ci s'exprimait certes dans les rituels d'investiture comme le sacre, mais aussi dans les élections. Dans ce contexte, le consentement unanime était requis dans le choix de la personne à élever. Conçue comme un moyen de découvrir la volonté de

CHERRIER : Histoire de la lutte des papes et des empereurs de la Maison de Souabe, de ses causes et de ses effets, Paris 1844, vol. 2, p. 87-96.

9 EIKE DE REPGOW: Sachsenspiegel des Eike von Repgow. Die Wolffenbütteler Bilderhandschrift. Cod. Guelf. 3.1 Aug. 20 ${ }^{0}$ éd. Ruth Schmidt-Wiegand, Berlin 2018. 
Dieu, l'élection était guidée par la règle de l'unanimité, la seule qui pouvait assurer aux participants que leur décision était la bonne ${ }^{10}$. Dès lors, dans l'Église et dans le contexte laïc, la pratique de l'élection par inspiration divine ${ }^{11}$ et le sens que prend l'expression Vox populi, vox Dei devenaient importants. ${ }^{12}$ En effet, c'était seulement au cours du XII ${ }^{\mathrm{e}}$ et $\mathrm{XIII}^{\mathrm{e}}$ siècle que, dans les elections ecclésiastiques puis seculières, la fiction légale selon laquelle la majorité representente la volonté de tous et, donc, la volonté générale a été développée. Ainsi, assez tardivement la procedure de compter les votes remplaça la mise en scène d'unanimité par le retrait du groupe plus faible qui avait auparavant laissé le champ d'action rituel aux vainqueurs tout en se reservant l'option de ne pas reconnaitre la légitimité de l'election à laquelle il n'avait pas participé.

En droit canonique, le libre choix a été hautement valorisé assez tôt. Déjà, au III ${ }^{\mathrm{e}}$ siècle, l'évêque Cyprien de Carthage (200/210-248/249) soulignait que lors de l'élection de l'évêque par le peuple, certes, Dieu, le détenteur de la véritable décision, parlait par la voix du peuple; mais la voix de Dieu devenait audible à celui à qui la décision était effectivement due. ${ }^{13}$ Le terme vox populi, vox Dei semble ainsi avoir son origine dans

${ }^{10}$ Josep M. Colomer/Iain MCLEAN : Electing Popes. Approval Balloting and qualifiedmajority Rule, The Journal of Interdisciplinary History 29.1 (1998), p. 1-22, ici: p. 3.

${ }^{11}$ V. JULEROT : < Y a ung grant désordre >. Élections épiscopales et schismes diocésains en France sous Charles VIII, Paris 2006, p. 73.

${ }^{12}$ Le principe de la royauté élective remonte au $\mathrm{V}^{\mathrm{e}}$ siècle avec le mythe de Pharamond, premier roi Franc d'origine germanique élu en 418. Cf. Jelle Koopmans : À l'ombre de Pharamond. La royauté élective, Cahiers de recherches médiévales et humanistes 20 (2010), p. 135-143. L'influence de la tradition biblique joue un grand rôle dans la vulgarisation de la à partir du haut Moyen Âge. Dans la Vulgate transmise aux chrétiens médiévaux, l'expression « Écoute la voix du peuple » (Audi vocem populi), dans I Samuel 8:7, est la réponse donnée par Dieu à son grand prêtre Samuel lorsque le peuple le rencontra pour lui demander un roi. Cette justification biblique fonde ainsi la théorie selon laquelle, au début, les rois ont été élus par le populus. Voir George BoAs: Art. «Vox populi », in: Dictionary of the History of Ideas, éd. Philip Paul Wiener, vol. 4, 1973-1974, p. 497-500; Alain Boureau : L'adage vox populi, vox Dei et l'invention de la nation anglaise (VIII $-\mathrm{XII}{ }^{\mathrm{e}}$ siècle), Annales. Économies, Sociétés, Civilisations 1992, p. 10711089; Alain Boureau : Art. «Vox populi, vox Dei », in: Dictionnaire du vote, éd. P. Perrineau/D. Reynié, Paris 2001, p. 965-967

${ }^{13}$ Takeo OSAWA: Das Bischofseinsetzungsverfahren bei Cyprian. Historische Untersuchungen $\mathrm{zu}$ den Begriffen iudicium, suffragium, testimonium, consensus 
l'élection au ministère ordonné. C'était la formule par laquelle, du point de vue de l'Église, toute occupation d'une fonction ministérielle ordonnée nécessitait d'être justifiée par une élection. Les évêques, quelle que soit leur nomination, devaient être approuvés par le peuple et le consentement populaire a été exprimé selon toute probabilité par acclamation. Le Décret de Gratien, composé vers le milieu du XII siècle', stipule en effet que «Le peuple n'élit pas mais consent à l'élection » (Plebi non est eligere set electioni consentire). ${ }^{14}$

Les sources historiographiques concernant l'élection des rois sont, cependant, moins claires. Pour les rois du haut et du bas Moyen Âge, conformément au consensus fidelium, l'approbation des grands de l'Empire par l'élection ou choix était un élément essentiel de la légitimation de leur pouvoir. Dans l'Occident latin, cependant, le noble argument de l'origine et de la descendance est tout aussi important. Contrairement à Byzance, où l'aristocratie impériale ne se distinguait pas principalement par son origine mais par ses possessions et ses fonctions, en Occident l'appartenance à une famille d'origine royale, la stirps regia, était considérée comme une condition capitale à la capacité de gouverner. ${ }^{15}$ Il était supposé qu'un roi digne de ce nom devait avoir un sang royal, mais il fallait encore que les hommes les plus puissants du royaume l'approuvent par election. Dans la représentation du bon ordre politique et social chez les seigneurs de l'Empire, ce pouvoir

(Europäische Hochschulschriften XXIII 178), Francfort/Bern 1983. Selon Osawa, qui fait siennes les pensées de Cyprian, le peuple, par opposition au clergé, n'avait pas le droit de coopérer activement et de prendre l'initiative de l'élection. Cyprian est souvent cité par les réformateurs de l'église aux $\mathrm{XI}^{\mathrm{e}}$ et $\mathrm{XII}{ }^{\mathrm{e}}$ siècles; cf. aussi Lexikon des Mittelalters, Munich 1986, vol. 3, p. 403.

${ }^{14}$ Paris, Bibliothèque Nationale de France nov. acq. lat. 1761, f. 64ra, cité par Kenneth Pennington: The Golden Age of Episcopal Elections 1100-1300, Bulletin of Medieval Canon Law 35 (2018), p. 243-253, ici : p. 245.

${ }^{15}$ Joseph CANNING : A History of Medieval Political Thought, 300-1450, Londres/New York 1996, p. 21-22. La signification de base de stirps est racine. Le mot induit, donc, l'idée d'ascendance, mais également celle de progéniture ou de descendance. Stirps regia renvoie, en somme, à la dynastie royale. Allusion est ainsi faite à la race dans le sens ancien du mot, et les trois races évoquent les racines des rois de France : Merovingiens, Carolingiens, Capétiens. Voir Jean-François LEMARIGNIER : La France médiévale. Institutions et sociétés, Paris 1970, p. 42-95. 
consensuel (konsensuale Herrschaft) ${ }^{16}$ a donné naissance à l'idée que la royauté, tout comme leur propre position dans l'Empire, se transmettait, certes, par hérédité, mais qu'un souverain ne pouvait entrer en fonction qu'avec le consentement exprès de ceux qui étaient directement sous ses ordres. Cette considération eut pour conséquence pratique cette idée de l'Église selon laquelle la voix de Dieu s'exprime dans le libre choix. Les deux idées étaient, dans la pratique, compatibles. Mais elles appartenaient à des systèmes de référence différents et pouvaient donc, surtout en théorie, donner lieu à des évaluations et des justifications différentes constatées dans la double élection de $1198 .{ }^{17}$

La possibilité d'une décision électorale se présentait, néanmoins, aux grands de l'Empire que si aucun successeur clairement légitimé par son origine n'était disponible. Ce fut le cas en Francie orientale depuis sa fondation au IX ${ }^{\mathrm{e}}$ siècle, à des intervalles de quatre générations au maximum. Dès lors, la participation des principes imperii (les grands ou les princes de l'Empire) était, au moins potentiellement, plus qu'une simple acclamation.

En France, par contre, l'évolution a été différente, car depuis le transfert de la royauté aux Capétiens à la fin du $\mathrm{X}^{\mathrm{e}}$ siècle, il y avait toujours un fils disponible et capable de gouverner lorsqu'un roi mourait. Ce «miracle capétien ${ }^{18}$ a finalement permis, à partir de la fin $\mathrm{du} \mathrm{XII}^{\mathrm{e}}$ siècle, de légitimer le règne du roi de France exclusivement par héritage et de faire tomber l'acte électoral des barons, désormais réduit

\footnotetext{
${ }^{16} \mathrm{Au}$ sujet de cette notion, voir Bernd SCHNEIDMÜLLER : Konsensuale Herrschaft. Ein Essay über Formen und Konzepte politischer Ordnung im Mittelalter, in : Reich, Regionen und Europa in Mittelalter und Neuzeit. Festschrift für Peter Moraw, éd. Paul-Joachim Heinig, Berlin 2000, p. 53-87; Hagen KeLLER : Grundlagen ottonischer Königsherrschaft, in: Reich und Kirche vor dem Investiturstreit. Vorträge beim wissenschaftlichen Kolloquium aus Anlass des achtzigsten Geburtstags von Gerd Tellenbach, éd. Gerd Tellenbach/Karl Schmid, Sigmaringen 1985, p. 17-34; Jürgen HaNNIG: Consensus fidelium. Frühfeudale Interpretationen des Verhältnisses von Königtum und Adel am Beispiel des Frankenreiches, Stuttgart 1982.

${ }^{17}$ Klaus VAN EICKELS: Otto IV. und Philipp von Schwaben, in: Die deutschen Herrscher des Mittelalters, éd. Bernd Schneidmüller/Stefan Weinfurter, Munich 2003, p. 272-292.
}

18 Le Miracle capétien, éd. Stéphane RiaLs, Paris 1987. 
tout simplement à l'acclamation. Puis, depuis le XIII ${ }^{\mathrm{e}}$ siècle, l'hérédité par primogéniture est devenue la coutume successorale dans la plupart des royaumes occidentaux. ${ }^{19}$

Peu de dynasties ont réussi à égaler les Capétiens qui ont connu une succession ininterrompue de pères en fils, de 987 à 1316. Par exemple, en Angleterre, une succession sans heurts, où le fils remplaçait son père sans rivalité ni dispute, était rare. Entre 1066 et 1216, on ne compte que deux exemples d'une succession directe de père en fils, lorsque Guillaume le Roux a succédé à Guillaume le Conquérant, en 1087, et Richard Cœur de Lion remplaçait Henry II, en 1189. D'ailleurs, ces deux successions n'ont été nullement paisibles ; elles étaient plutôt le resultat d'âpres disputes liées aux contestations et aux conflits exacerbés. Guillaume le Conquérant aurait bien voulu déshériter son fils aîné rebelle Robert Curthose, mais il ne pouvait disposer librement que du royaume d'Angleterre qu'il avait conquis. Les quatre fils de Henri II avaient férocement lutté entre eux et contre leur père pour leur part de l'héritage et Henri II se méfiait tellement de Richard qu'il fallait une défaite militaire desastreuse pour le contraindre à le reconnaitre comme son héritier unique. ${ }^{20}$

Cette tendance à une monarchie héréditaire plutôt qu'à celle élective, défendue en Europe du Nord et centrale, est illustrée dans un manuscrit français intitulé Avis aus Roys, ou livre de conseils royaux, datant du milieu du XIV $\mathrm{X}^{\mathrm{e}}$ siècle et probablement réalisé pour Louis, duc d'Anjou (1339-1385).

\footnotetext{
${ }^{19}$ Toutefois, quoique la seule succession héréditaire restait pleinement en usage depuis l'avènement de Philippe III, en 1270, c'est seulement sous Charles V (1364-1380) que des contours juridiques ont été donnés au principe héréditaire d'accession au trône, dans son édit d'août 1374. Cf. Ordonnances des rois de France de la troisième race. Sixième volume contenant les ordonnances de Charles V, éd. Denis-François Secousse, Paris 1741, p. 26. On trouvera un important éclairage sur cette ordonnance chez Françoise AUTRAND : La succession à la couronne de France et les ordonnances de 1374, in : Représentation, pouvoir et royauté à la fin du Moyen Âge, éd. Joël Blanchard, Paris 1995, p. 25-32.

${ }^{20}$ Klaus van Eickels : Vom inszenierten Konsens zum systematisierten Konflikt. Die englisch-französischen Beziehungen und ihre Wahrnehmung an der Wende vom Hochzum Spätmittelalter, Stuttgart 2002, p. 65-67 et 91.
} 


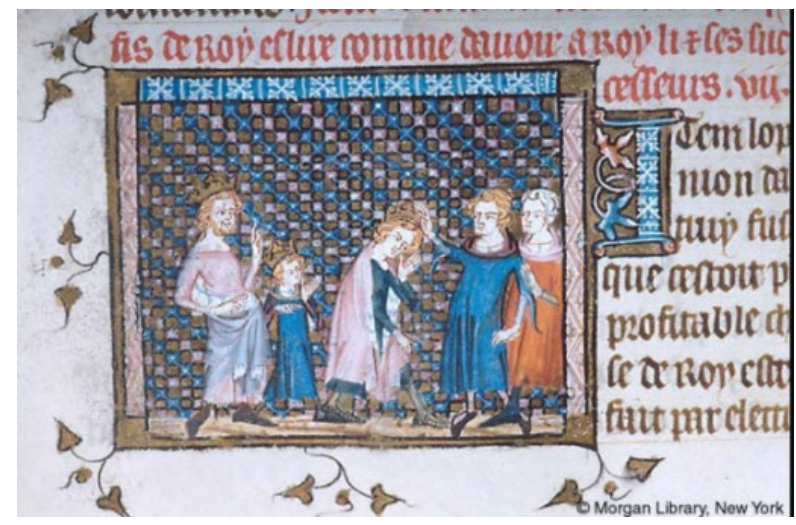

Fig. 1 : Un jeune roi couronné par le peuple.

Source : Avis aus Roys, Pierpont Morgan Library, ms. 456, f. 82v.

L'auteur possible du texte dans lequel est inséré l'enluminure est Pierre de Treigny ( $† 1356)$, le confesseur royal des rois Philippe VI et Jean II de France. Ce livre souligne les avantages de l'adhésion à la succession royale héréditaire. Elle était largement considérée comme un transfert de pouvoir plus sûr et plus facile à gérer que les autres moyens de choisir un souverain. C'est pourquoi on peut voir sur cette scène le vieux roi qui désigne, en le montrant du doigt, son successeur. Le couronnement du jeune roi par le peuple à travers les puissants seigneurs souligne alors son élection.

La position de l'Église est sans ambiguité. En effet, l'ascendance royale est certes nécessaire, mais du point de vue de l'Église, le libre choix est encore plus important que la coïncidence biologique de l'ascendance. En 1200, Innocent III, qui ambitionnait de soumettre les souverains temporels (potestas) à l'autorité pontificale (auctoritas), écrivait aux princes de l'Empire que c'était contre la «liberté de l'Empire »si quelqu'un usurpait la couronne «par droit d'héritage » (iure hereditario). Pour le pape, si le fils continuait à succéder au père, le frère au frère, le trône impérial ne serait plus électif, mais se transmettrait par droit héréditaire (Videretur Imperium ei non ex electione conferri, sed ex 
successione deberi). ${ }^{21}$ Il fallait donc éviter autant que possible une succession directe père-fils, afin de ne pas donner l'impression que l'Empire était une monarchie héréditaire comme n'importe quel autre royaume. Le pape avait un intérêt de souligner l'importance de l'élection libre car, dans le droit canonique, c'est la voie par laquelle Dieu peut exprimer sa volonté à travers le vote unanime des électeurs rassemblés au nom de Dieu et ayant la bonne intention d'entendre la voix du Saint Esprit. $^{22}$

Cependant, le contexte doit être pris en compte. La mort de l'empereur Henri VI en 1197 créât un vide de pouvoir. Il laissait un fils mineur, le futur Frédéric II, élu roi déjà à l'âge de deux ans au moment du depart de son père en croisade. Lorsque Henri VI meurt, son frère Philippe de Souabe était déjà en route pour l'Italie. Son objectif était d'y récupérer le petit Frédéric II afin de l'amener en Allemagne pour son couronnement. Les évéments en Italie ayant empêché cette mission, deux groupes de princes allemands procédaient, en 1198, à deux élections royales. Dans un empire sans constitution écrite ni autorité suprême fonctionnant comme une cour constitutionnelle, les deux groupes pouvaient se présenter comme des acteurs légitimes. Philippe de Souabe, l'oncle de Frédéric, était sans doute soucieux de préserver la

${ }^{21}$ INNONCENT III, Deliberatio, éd. Kempf, p. 83.

${ }^{22}$ Cependant, les électeurs étant faillibles et animés par des motivations diverses susceptibles de rendre difficile, voire impossible, un consensus, les médiévaux conservaient une tout autre option pour déterminer la volonté de Dieu. Pour les laïcs, le duel judicaire intervenait comme le moyen de savoir le jugement de Dieu. C'était une sorte de procès dans lequel la décision finale était fixée par l'issue du combat entre les deux adversaires (Le règlement des conflits au Moyen Âge. Actes du XXXI ${ }^{\mathrm{e}}$ Congrès de la SHMESP, Publication de la Sorbonne, Paris 2001. En accès libre sur https://www.persee.fr/issue/shmes_1261-9078_2001_act_31_1). C'est seulement depuis le XIII ${ }^{\mathrm{e}}$ siècle que le recours au pape, en tant que le représentant du Christ sur terre, a été ajouté comme une solution alternative, surtout sous l'influence d'Innocent III, avec son Decretalis de iure pontificis in electione regis, in: MGH Const., éd. Ludwig Weiland, Hanovre 1896, vol. 2, $\mathrm{n}^{\circ} 398$, p. 505-507. K. Pennington en a donné une traduction et analyse sous le titre Decretal Letters of Pope Innocent III touching on Church and State, http://legalhistorysources.com/ChurchHistory220/Lecture\%20Four/InnocentIIIChurchSt ate.html . Dans ce document, le pape se défendait légitimement contre l'accusation d'avoir restreint la liberté des princes impériaux en s'immisçant dans l'élection du roi des Romains. 
couronne de son neveu. Mais abandonant vite sa cause, il fut élu par le plus grand nombre des princes les plus puissants. Quant à Otton de Brunswick, il obtint les suffrages d'un groupe beaucoup plus restreint, qui avait pourtant à leur tête l'archévêque de Cologne. Lui seul avait le droit de couronner le nouveau roi des Romain sur le trône de Charlemagne à Aix-la-Chapelle.

Dans la bataille pour la reconnaissance de leur règne, les deux rois élus tentèrent de gagner le conflit grâce au soutien des autres rois européens - Philippe Auguste de France se déclara pour Philippe de Souabe et Richard Cour de lion d'Angleterre, pour Otton-, mais également de l'appui papal. Innocent III avait justifié son intervention dans la dispute en faisant valoir qu'il devait, plus tard, couronner empereur le roi choisi par les princes allemands. Il avait donc revendiqué le droit d'examiner l'idonéité des trois rois élus (Frédéric, mineur au nom duquel sa mère avait déjà renoncé à la couronne de l'Empire; Philippe de Souabe et Otton de Brunswick) sous le triple rapport du droit, de la convenance et de l'utilité. Il recommandait aux princes allemands, après avoir déduit les motifs qui, selon lui, devaient faire exclure Philippe de Souabe et Frédéric, de réunir leurs suffrages sur une même personne ou qu'ils s'en rapportent à la décision arbitrale de la cour apostolique. Cherchant un argument contre Philippe qui réclamait la couronne en tant que fils et frère de ses prédécesseurs, donc par droit d'héritage, le pape Innocent III reconnut finalement Otton IV pour roi des Romains. Dans cette affaire, la revendication papale a été controversée pour la simple raison que le pape n'était pas intervenu dans le conflit en tant qu'un juge neutre, mais seulement à l'initiative de l'une des deux parties et naturellement à la demande de la partie la plus faible, car la partie plus forte espérait l'emporter par la force des armes. $^{23}$

Si l'on examine les élections royales des $\mathrm{XI}^{\mathrm{e}}$ et $\mathrm{XII}^{\mathrm{e}}$ siècles, il est frappant de constater qu'elles se sont déroulées dans le désordre. Une

\footnotetext{
${ }^{23}$ VAN EICKELS : Otto IV. und Philipp von Schwaben, p. 272-292; Friedrich KEMPF : Innocenz III. und der deutsche Thronstreit, Archivum Historiae Pontificiae 23 (1985), p. 63-91.
} 
procédure de décision n'existait pas. En cas de décès d'un roi sans fils, les contemporains se retrouvaient dans la situation d'une succession non clairement définie par un droit successoral. Une élection devait alors régler le problème. Toutefois, les sources ne contiennent aucune information précise relative aux personnes ayant le droit de vote, ni à la manière dont elles devaient voter, obligeant ainsi à scruter les détails. Ce faisant, un certain nombre de différences importantes peuvent être constatées entre la représentation médiévale de la royauté élective et les idées modernes de l'élection.

\subsection{L'humilité chrétienne et l'absence d'une culture du refus dans l'élection}

Contrairement à ce que l'on peut observer aujourd'hui, aucun candidat ne se présentait aux élections. L'humilité chrétienne recommandait de ne pas aspirer ou s'efforcer à une élévation en grade. On connait l'exemple de saint Martin qui, en 372, a tellement résisté à son élection comme évêque de Tours, qu'il a même fini par essayer d'échapper à la pression du peuple en se réfugiant dans une maison d'oies. ${ }^{24}$ L'élection de Saint Augustin comme prêtre et futur évêque d'Hippone en 391 en est un autre exemple. Il pleura et refusa obstinément d'accepter l'ordination et le ministère, mais il y fut finalement contraint. ${ }^{25}$

Éginhard souligne, dans son récit sur le couronnement impérial de Charlemagne le jour de Noël en l'an 800, que le roi des Francs ne serait pas entré dans l'église malgré la grande fête s'il avait su que le pape Léon III (795-816) prévoyait de le couronner empereur. ${ }^{26}$ Après la conquête de Jérusalem, les deux chefs de la première croisade Raymond IV de Toulouse et Godefroy de Bouillon - se sont également manifestés dans des gestes d'humilité chrétienne. Jérusalem prise en juillet 1099, les barons se réunirent pour choisir le seigneur qui en aura

\footnotetext{
24 Kirchenpatrone Deutschfreiburgs, Gerhard BAECHLER/Erich CAMENZIND, Fribourg 1989, p. 128.

${ }^{25}$ Carl Bindemann : Saint Augustin, Revue de théologie et de philosophie et compterendu des principales publications scientifiques 9 (1876), p. 414-444, en part. p. 425.

${ }^{26}$ ÉGINHARD : Vie de Charlemagne, éd. et trad. Louis Halphen, Paris 1923, p. 81.
} 
la garde. Lorsqu'il réalisa que l'élection ne se ferait pas en sa faveur, bien qu'il ait légitimement droit au trône, Raymond fit savoir qu'il ne voulait pas porter la couronne au lieu même où le Christ avait été couronné d'épines. Godefroy de Bouillon, élu par les princes, pareillement, s'est abstenu d'un couronnement royal et a plutôt régné sur le royaume de Jérusalem en tant que < Bailli du Saint Sépulcre >. Ce titre était donné pour la première fois à un dirigeant chrétien en Terre Sainte. ${ }^{27}$

Ajoutons à ces exemples le récit d'un auteur anonyme au sujet de l'élection de Lothaire III en 1125, donné dans la Narratio de electione Lotharii. ${ }^{28}$ Le texte informe que sur l'initiative de l'archevêque Adalbert de Mayence un comité d'arbitrage composé de dix princes, issus de chacun des duchés de Bavière, de Souabe, de Franconie et de Saxe, fut mis en place. Il leur a été demandé de nommer trois d'entre eux qui devront choisir un parmi le trio pour être le roi des Romains. Le comité délégua cette tâche au duc Frédéric II de Souabe, au margrave Léopold III d'Autriche et au duc Lothaire de Saxe. Frédéric était, par l'intermédiaire de sa mère Agnès de Waiblingen issue de la dynastie franconienne, un neveu du défunt empereur Henri V. La position du Léopold était au moins renforcée par le fait qu'il avait épousé Agnès entre-temps. L'archevêque Adalbert de Mayence demanda aux trois candidats s'ils se soumettraient à la procédure en promettant solennellement d'obéir à celui qui serait élu. Lothaire a humblement décliné l'offre, vu son âge avancé. Il a, néanmoins, promis de reconnaître la décision électorale, comme l'a fait Léopold. D'ailleurs, ils ont protesté en larmes qu'aucun des deux voulait devenir roi. Le duc Frédéric, en revanche, estimait avoir un droit de succession, car à travers sa mère il pouvait réclamer, en tant qu'héritier, les possessions territoriales de l'empereur salien mort sans enfants. Il répondit de manière évasive qu'il ne pouvait prendre une décision sans l'avis de ses

\footnotetext{
27 The First Crusade, éd. Peters, p. 249, 274; The First Crusade, éd. Krey, p. 262-263.

${ }^{28}$ Narratio de electione Lotharii, éd. Pertz, p. 510-511. Un premier récit de cette élection avait été rédigé environ dix ans après l'événement par VITALIS : The Ecclesiastical History, livre 13, p. 360-655. Indispensable pour l'analyse de ces récits: Ulrich NonN: Geblütsrecht, Wahlrecht, Königswahl.Die Wahl Lothars von Supplinburg 1125, Geschichte in Wissenschaft und Unterricht 44 (1993), p. 146-157.
} 
fidèles. Il se retira donc de la réunion, parce qu'il se rendait compte qu'il ne pouvait pas compter sur une élection unanime. Le lendemain, Lothaire et Léopold ont été invités à décider du choix du roi, mais ils continuèrent à se nommer l'un l'autre. Finalement, les princes réunis perdirent patience et certains crièrent que Lothaire devait être roi, ce à quoi il consentit, mais à contrecœur et humblement. L'archevêque confirma l'élection.

Ces exemples montrent que la pratique exigeait de ne pas postuler la fonction de roi. Il fallait se laisser imposer ou l'exiger si le droit légal sur la charge était menacé. Le fait qu'un roi n'acceptait sa dignité qu’à contrecœur et sous la pression est une attitude qui participe de l'idéal médiévale de la royauté. De même, l'attitude des princes assemblés qui pressaient le candidat d'assumer la responsabilité pour laquelle ils l'avaient choisi est un comportement censé démontrer l'aptitude de la personne choisie. L'hésitation permettait également de s'assurer que l'élu avait bien le soutien total de son peuple. ${ }^{29}$

Aussi faut-il considérer l'effet contraignant d'une décision électorale. Elle ne s'applique qu'à ceux qui participent à l'élection et qui s'engagent expressément à se soumettre à la décision de la majorité. L'église et les laïcs convergeaient leur point de vue sur le principe d'un vote unanime 1: si la voix du peuple doit être la voix de Dieu, la décision doit être unanime et obtenue dans la concorde, car Dieu ne peut parler que d'une seule voix. Or si pour le laïc, l'élection est en même temps un hommage précoce au futur dirigeant, il est tout aussi indispensable qu'à la fin tous les participants se joignent à la décision, car celui qui refuse l'élection du nouveau dirigeant, en ne participant pas à l'acclamation jubilatoire, se rebelle ainsi contre lui. La crainte de ne pas obtenir l'unanimité peut avoir ainsi dicté les menaces de l'archevêque de Mayence lors de l'élection de Lothaire III en $1125 .{ }^{30}$ Un résultat divisé

\footnotetext{
${ }^{29}$ Björn WEILER : The rex renitens and the Medieval Ideal of Kingship, ca. 900-ca. 1250, Viator 31 (2000), p. 1-42.

30 ORDERICUS VitAlis : The Ecclesiastical History, livre 13, p. 362: « si l'un d'entre vous est en désaccord avec la décision commune, il sera immédiatement décapité, afin que la sainte assemblée des chrétiens ne soit pas perturbée par l'obstruction d'un seul homme »
} 
signifiait que les candidats ou les électeurs ignoraient la volonté de Dieu. D'une façon ou d'une autre, l'unanimité devait donc être obtenue.

Par ailleurs, l'établissement d'un consensus parfait parmi les membres de l'assemblée et son expression ritualisée dans le processus d'élection et d'élévation du nouveau roi étaient facilités par l'absence d'une culture du refus, c'est-à-dire par une dissidence pacifique. Pouvoir dire non, mais sous une forme qui n'interfère pas avec les bases de la communication, était considéré comme une compétence sociale cruciale dans la société bourgeoise occidentale des $\mathrm{XIX}^{\mathrm{e}}, \mathrm{XX}^{\mathrm{e}}$ et $\mathrm{XXI}^{\mathrm{e}}$ siècles. $\mathrm{Au}$ Moyen Âge européen - comme dans beaucoup de sociétés traditionnelles basées sur le rang, et cela s'observe en Afrique jusque de nos jours -, en revanche, tout rejet ouvert d'une demande ou d'une requête était perçu comme une atteinte à son propre honneur. ${ }^{31}$ Pour l'élection d'un nouveau roi, les nobles évitaient donc de s'exposer au risque d'avoir à exprimer un refus. Ceux qui soupçonnaient une décision électorale en leur défaveur se retiraient de l'assemblée. Ce faisant, ils permettaient aux autres grands seigneurs d'élire à l'unanimité leur candidat. Ils gardaient ainsi ouverte la possibilité de se réunir à un autre lieu pour élire un autre candidat, également à l'unanimité. ${ }^{32}$

Le processus électoral, lors des élections royales des $\mathrm{XI}^{\mathrm{e}}$ et $\mathrm{XII}^{\mathrm{e}}$ siècles, n'était donc pas un processus de décision permettant de clarifier pacifiquement la question de savoir qui devait succéder au trône. C'était plutôt un rituel dans lequel les électeurs exprimaient leur consensus avec le souverain à élever. Il n'était pas nécessaire de délimiter

(porro si quis uestrum a communi discrepauerit edicto, decolletur continuo, ne per unius proteruiam Christianorum perturbetur sancta concio).

${ }^{31}$ La structure d'une cour royale médiévale a, donc, été largement conçue pour épargner au souverain la nécessité de dire non. Les demandes et les requêtes étaient d'abord présentées au roi par des intermédiaires, notamment la reine ou d'autres confidents ayant un accès direct au souverain. Ce n'est que lorsqu'il a été notifié que le dirigeant accepte la demande que le pétitionnaire était autorisé à l'approcher. Au sujet de la compétence sociale de la communication au Moyen Âge, voir Pierre CHAPLAIS : English Medieval Diplomatic Practice, vol. 1 : Documents and Interpretation, Londres 1982.

${ }^{32}$ La double élection de 1198 s'inscrit dans cette logique ; cf. VAN EICKELS : Otto IV. und Philipp von Schwaben, p. 272-292. 
l'électorat, puisque l'élection devait de toute façon être unanime. De cette façon, il devient évident qu'au XII ${ }^{\mathrm{e}}$ siècle, tous les nobles de l'Empire, qui étaient en relation directe avec la royauté, avaient le droit de voter pour le roi.

\section{Le principe de l'élection libre dans l'Église transféré à l'élection du roi des Romains}

À partir du $\mathrm{XI}^{\mathrm{e}}$ siècle, l'Église avait initié en son sein des reformes visant le libre choix des dirigeants. Durant l'Antiquité tardive, l'élection de l'évêque par «le clergé et le peuple » s'était établi comme la norme. Pourtant, elle tombait en désuétude durant le haut Moyen Âge, particulièrement à l'époque ottonienne et salienne, quand les rois et les empereurs nominaient et investissaient sans hésitation les évêques. Également, dans la majorité des abbayes la famille du fondateur se réservait le droit de nommer l'abbé ou de confier à un membre laïc de la famille ses fonctions. Expérimentée avec succès par l'abbaye de Cluny au $\mathrm{X}^{\mathrm{e}}$ siècle, l'élection libre, adoptée comme principe par l'Église au cours de la reforme grégorienne du $\mathrm{XI}^{\mathrm{e}}$ siècle, fut introduite pour les élections épiscopale dans l'Empire au XII ${ }^{\mathrm{e}}$ siècle et transférée à l'élection du roi des Romains aux XIII ${ }^{\mathrm{e}}$ et XIV ${ }^{\mathrm{e}}$ siècles.

\subsection{Les monastères réformateurs influencent l'idée du libre choix dans l'Église}

Alors que le lien de sang et le principe d'hérédité interviennent dans la légitimité royale, la chasteté, observée dans l'Église, a exigé d'inventer un autre système de transmission de l'autorité, à savoir le libre choix. Au cours du XIII ${ }^{\mathrm{e}}$ siècle, cependant, la nécessité s'est imposée d'harmoniser cette idée séculière de l'élection, comprise comme un rituel du consensus, avec l'idée canonique des critères de l'élection libre, développés pendant la Querelle des investitures et la réforme de l'Église depuis le $\mathrm{XI}^{\mathrm{e}}$ siècle.

L'idée du libre choix dans le remplissage des offices religieux a été, en effet, influencée de manière décisive par les monastères réformateurs, surtout par l'abbaye de Cluny en France. En 910, le duc 
Guillaume III d'Aquitaine fit don aux apôtres Pierre et Paul d'une partie de son alleu sis dans le comté de Mâcon. ${ }^{33}$ Par cette donation, qui institue l'abbaye de Cluny, Guillaume III renonçait à tout droit vis-à-vis du monastère. Ce legs impliquait également qu'il accordait à l'abbaye le droit de choisir librement son abbé.

Le mode d'élection alors choisi par les moines fut celui de l'unanimité (unanimitas) selon la règle de saint Benoît rédigée au $\mathrm{VI}^{\mathrm{e}}$ siècle et réaffirmée à partir $\mathrm{du} \mathrm{XI}^{\mathrm{e}}$ siècle. Elle stipule que soit institué comme abbé celui que toute la communauté, selon la crainte de Dieu, élit d'un commun accord ou celui qui a été choisi par la sanior pars. ${ }^{34}$ Ainsi, dans le cas où l'unanimité est impossible à atteindre, l'abbé élu par la part «plus saine» par rapport au conseil (sanior consilio) de l'assemblée est désigné, même si elle n'est guère qu'une très petite minorité. ${ }^{35}$ Par cette règle, il fallait être avant tout l'élu de la sanior pars, c'est-à-dire qu'il fallait obtenir l'appui des plus sages et des meilleurs. Comme dans beaucoup de sociétés traditionnelles actuelles, les votes n'étaient pas comptés mais pesés. Vu le poids de leurs suffrages, la minorité des plus dignes et respectés notables constitue, à vrai dire, la majorité (maioritas). Employées dans un sens qualitatif et non pas

33 Les plus anciens documents originaux de l'abbaye de Cluny, éd. Hartmut Atsma/S. Barret/Jean Vezin, Paris 1997, Bibliothèque Nationale de France (Monumenta Palaeographica Medii Aevi. Series Gallica), vol. I.4, p. 34: « Pour l'amour de Dieu et de notre sauveur Jésus-Christ, je transmets en domination propre des biens qui sont de mon droit aux saints apôtres Pierre et Paul, c'est-à-dire le domaine de Cluny avec le curtil et le manse de la réserve, la chapelle en l'honneur de sainte Marie mère de Dieu et de saint Pierre, prince des apôtres, et tous les biens qui en dépendent, c'est-à-dire les domaines, chapelles, serfs de l'un et l'autre sexe, vignes, champs, prés, forêts, plans d'eau et cours d'eau, moulins, chemins d'accès et de sortie, terres cultes et incultes, le tout en intégralité » (ob amorem Dei et Salvatoris nostri Jesu Christi, res juris mei sanctis apostolis Petro videlicet et Paulo de propria trado dominatione, Clugniacum scilicet villam, cum cortile et manso indominicato, et capella quae est in honore sancte Dei genitricis Mariae et sancti Petri, apostolorum principis, cum omnibus rebus ad ipsam pertinentibus, villis siquidem, capellis, mancipiis utriusque sexus, vineis, campis, pratis, silvis, aquis earumque decursibus, farinariis, exitibus et regressibus, cultum et incultum, cum omni integritate).

${ }^{34}$ Jean GAUDEMET : Les élections dans l'Église latine. Des origines au XVI ${ }^{\mathrm{e}}$ siècle, Paris 1979, p. 217.

${ }^{35}$ Guy HERMET : Les sources chrétiennes de la démocratie. La liberté par mégarde, Paris 2020, p. 71. 
quantitatif, la saniorité (sanior pars) et la maioritas sont, toutes deux, une expression de l'excellence. ${ }^{36}$

Dans la pratique, afin de ne pas laisser le moindre prétexte d'une querelle dans la communauté et vu qu'il n'était pas évident d'imposer à une minorité récalcitrante l'élu de la majorité et encore moins à une majorité l'élu d'une sanior pars autoproclamée, les moines procédaient à un vote par acclamations. La résistance des moins âgés et moins respectables s'éteignant face à l'autorité des plus sages et des meilleurs, on débouchait de toute évidence sur une déclaration d'unanimité. Donc, la décision électorale par acclamations et avec l'assentiment de la communauté était la règle d'or. ${ }^{37}$ Ce mode d'élection était d'autant plus important que la question de la délimitation de l'électorat ne se pose pas véritablement dans un monastère. On a affaire à une communauté fermée capable de régler ses affaires internes à huis-clos. De plus, il y avait un ordre de préséance reconnu au sein du monastère, déterminé par la hiérarchie des offices et l'ancienneté. La question de savoir qui vote et dans quel ordre vote-t-on a été, par conséquent, clairement définie. ${ }^{38}$ Les moines étaient également tenus de reconnaître le résultat de l'élection. La possibilité de faire sécession, en s'éloignant afin d'élire un autre candidat ailleurs, ne leur était pas donnée.

Le modèle de Cluny s'est avéré réussi. Cela ne pouvait être autrement, car les monastères, qui échappaient à l'influence de la famille fondatrice et qui pouvaient nommer leurs propres abbés, étaient obligés de suivre exclusivement le mandat de leur patron spirituel. L'observation démonstrative et pour tous visible de la règle de l'ordre, dont celle de saint Benoît en ce qui concerne Cluny, était dans l'intérêt des monastères. C'était seulement de cette manière qu'ils pouvaient

\footnotetext{
${ }^{36}$ HERMET : Les sources chrétiennes de la démocratie, p. 71; GAUDEMET : Les élections dans l'Église latine, p. 217; Léo Moulin: Sanior et maior pars. Note sur l'évolution des techniques électorales dans les Ordres religieux du VI ${ }^{\mathrm{e}}$ au XIII ${ }^{\mathrm{e}}$ siècle, Revue historique de droit français et étranger, Quatrième série 35 (1958), p. 491-529.

${ }^{37}$ Moulin : Sanior et maior pars, p. 492.

38 Moulin : Sanior et maior pars, p. 491-529.
} 
s'affirmer sur le marché comme des prestataires fiables du service de la prière d'intercession et susciter d'autres fondations.

Influencée par l'expérience de Cluny, l'institution d'un collège de cardinaux électeurs et d'un conclave papal fut adoptée par l'Église sur le principe du libre choix.

\subsection{De l'élection libre au « conclave des horreurs » de 1241}

Les Ottoniens, qui régnèrent à la tête du Saint-Empire romain germanique de 962 à 1024, ont exercé un contrôle total sur l'élection des papes et sur la nomination des évêques dans l'Empire. Ils donnèrent les investitures spirituelles à des prélats de leur choix, ${ }^{39}$ de sorte que les évêques de l'Église impériale formèrent l'ossature de l'administration impériale. Les monastères royaux, les grands chapitres séculiers étaient aussi concernés par la pratique. Cette organisation fut maintenue jusqu'au règne de l'empereur Henri III (1017-1056). En décembre 1046, il déposa quasi simultanément trois papes concurrents au Synode de Sutri, pour en nommer un de son choix. ${ }^{40}$ Inspiré par les idées d'une reforme de l'Église selon le model de Cluny, Henri III nomma des évêques issus de l'Église imperiale et installés grâce à son soutien en

${ }^{39}$ Ainsi l'élection de Walthard à l'archevêché de Magdebourg en 1012 par Henri II. L'anneau qu'il reçut du roi romain comme gage de sa grâce future indiquait qu'il était l'évêque choisi par le roi. Puis il fut investi dans sa charge par la remise de la crosse, avant d'être acclamé par les grands et consacré à l'église. Cf. THIETMAR vON MERSEBURG: Chronik, retranscrite et expliquée par Werner Trillmich (Ausgewählte Quellen zur deutschen Geschichte des Mittelalters, Freiherr vom Stein-Gedächtnisausgabe, 9), Darmstadt 2011, p. 315, 317.

${ }^{40}$ Rappelons les grandes lignes des faits. Le pape Benoît IX est renversé en 1044 par une révolte de la population romaine. Il est remplacé par l'évêque de Sabine, qui prit le nom de Sylvestre III. Ces deux papes appartiennent à des factions rivales de la noblesse romaine. Par la force des armes, Benoît IX réussit à le chasser en 1045, mais il cède le siège pontifical à Jean Gratien, un prêtre romain. Ayant «acheté » son titre moyannant une recompense pour son prédecesseur resigné, celui-ci fut proclamé pape sous le nom de Grégoire VI. En 1046, soucieux de mettre un terme à l'anarchie papale et à la simonie dans l'église, mais aussi d'assurer la validité de son couronnement impérial par un pape non contestable, Henri III descend sur Rome. Il dépose Grégoire VI, Sylvestre III et Benoît IX, puis il nomme l'évêque Suidger du diocèse de Bamberg, devenu Clément II. Voir Jacques van WiJNENDAELEL Silences et mensonges autour d'un concile. Le concile de Sutri (1046) en son temps, Revue belge de philologie et d'histoire 83/2 (2005), p. 315-353. 
tant qu'empereur. Ces prélats étaient toutefois déterminés à lutter contre la vénalité des offices et le mariage des prêtres - la simonie et le nicolaïsme -, afin de rendre l'Église autonome et indépendante de l'ingérence des laïcs et surtout de la mainmise des familles de la noblesse urbaine de Rome sur la papauté. Cette initiative semblait, au début, vouée à l'échec, car les prémiers papes reformateurs d'orgine allemande installés eurent la tache diffcile. Soit-il supportaient mal le climat italien et le paludisme, soit ils se faisaient empoisonner, selon la rumeur, par les ennemies de la reforme à Rome. Ces papes n'avaient donc pas des pontificats assez longs pour réussir un profond changement. Seuls Léon IX (1049-1054) et Victor II (1055-1057) régnèrent suffisamment longtemps pour implémenter véritablement la réforme au sein de l'Église romaine.

À la mort de Henri III, son fils et successeur Henri IV était encore mineur. Après celle subite de Victor III (1086-1087), les reformateurs, qui s'étaient emparés des positions essentielles du pouvoir, devaient, pour la première fois, assurer la poursuite de leur projet contesté de réagencement de l'Église sans avoir recours à un empereur fort qui les soutenait.

Après le court pontificat d'Étienne IX, le pape Nicolas II (1058-1061) fut élu de façon contestable par les cardinaux qui, face à une forte opposition à Rome, s'étaient rétirés à Siène. Étienne IX faisait donc face au défi de légitimer son pouvoir sans avoir l'option de recourir à l'autorité impériale. Aussi, décréta-t-il le 13 avril 1059, dans la bulle pontificale In nomine Domini, que désormais seuls les cardinaux-évêques devaient élire le pape, mais également un évêque romain. Quant à la participation du reste du clergé et du peuple, elle restait limitée au droit de consentement par acclamation. ${ }^{41}$ Dès lors, l'occupation des fonctions ecclésiastiques par élection libre devint, dans le droit canonique des $\mathrm{XI}^{\mathrm{e}}$ et $\mathrm{XII}^{\mathrm{e}}$ siècles, la base décisive de la «liberté de l'Église» (libertas ecclesiae). Les réformateurs de l'Église, qui prirent le contrôle du siège de l'Église latine dans le milieu du $\mathrm{XI}^{\mathrm{e}}$ siècle, sont partis de la phrase

${ }^{41}$ Pennington : The Golden Age. 
traditionnelle du Pape Léon $\mathrm{I}^{\text {er }}$ (440-461), selon laquelle personne ne devait devenir évêque s'il n'était pas élu par le clergé de son diocèse, exigé par le peuple et confirmé par le Métropolitain, c'est-à-dire par l'archevêque responsable dudit diocèse. ${ }^{42}$ Pour ces réformateurs, l'élection libre était la procédure électorale qui garantit des résultats clairs, mais également un moyen d'améliorer les conditions au sein de l'Église.

Le décret du pape Nicolas II connut un développement, surtout qu'à partir du $\mathrm{XI}^{\mathrm{e}}$ siècle la majorité de la chrétienté occidentale croyait de plus en plus que l'élection du pape devait être unanime. Un seul vote négatif pouvait devenir un motif de contestation de la légitimité d'un pape et donner lieu à un schisme. En 1159, Alexandre III (†1181) fut élu pape, mais la dissidence d'une minorité de cardinaux conduisit à un schisme qui dura des décennies. En 1179, s'appuyant sur l'expérience de son élection et reprenant le modèle de Cluny, il établit la règle selon laquelle les papes devaient désormais être élus uniquement par les cardinaux des trois ordres: les cardinaux-évêques titulaires d'un évêché voisin de Rome; les cardinaux-prêtres détenteurs d'une paroisse romaine; les cardinaux-diacres responsables d'une diaconie romaine. Adoptée à l'occasion de l'un des plus importants conciles de l'Église médiévale, le III $^{\mathrm{e}}$ concile du Latran, cette règle, endcore en vigueur, stipule que le candidat élu par les deux tiers des cardinaux doit, en tout état de cause,

\footnotetext{
${ }^{42}$ Papal elections of the $11^{\text {th }}$ Century (1061-1099), http://cardinals.fiu.edu/conclavexi.htm. Voir également Pennington: The Golden Age; Frederic J. BaumgarTner : Behind Locked Doors. A History of the Papal Elections, Londres 2003, p. 19-24. La bulle In nomine Domini accordait néanmoins un contrôle impérial, mais il était limité à un droit personnel accordé par le pape pour confirmer les élections papales. C'est dire que les réformateurs grégoriens ne refusaient pas à l'empereur tout rôle, mais ils lui reconnaissaient une autorité subordonnée à celle du pontife romain. Le principe de l'élection libre, basé sur la libertas ecclesiae, définit ainsi les autorités habilitées à participer au choix épiscopal. La restriction aux seuls cardinaux-évêques vise, donc, à évincer les Grands désormais réduits à approuver le choix et ratifier une désignation faite par les clercs. Cf. Brigitte BASDEVANT-GAUDEMET : Quelques réflexions sur la < Libertas Ecclesiae > dans les procédures de désignations épiscopales au cours des siècles, Revue historique de droit français et étranger 94/1 (2016), p. 13-25.
} 
être légitimement le nouveau pape. ${ }^{43}$ Le droit de suffrage réservé au collège des cardinaux, doublé de la décision de vote aux deux tiers minimum et de l'exclusion d'une minorité de se déclarer sanior pars, constituait une avancée notable éliminant définitivement le risque d'un schisme. Pourtant, le progrès avait un prix : l'exclusion d'une élection contestable par une faible majorité impliquait la forte probabilité d'un long processus d'accord sur un candidat, de nombreux scrutins sans résultat valable et, par conséquent, une durée excessive de la sedisvacance.

Ce danger a d'abord été rencontré par les pouvoirs séculiers, comme le souligne la création de conclaves laïcs pour l'élection des magistrats. C'était une procédure courante dans les villes du nord de l'Italie visant à accélérer le processus décisionnel des organes municipaux. Le but était également de soustraire le collège électoral à de multiples pressions, afin d'assurer l'impartialité complète des électeurs. ${ }^{44}$ L'un des premiers conclaves laïcs documentés date du jeudi 23 mars 1223 à Plaisance. Selon le récit détaillé d'une chronique anonyme italienne, ${ }^{45}$ le podestat ${ }^{46}$

${ }^{43}$ Joseph F. Kelly: The Ecumenical Councils of the Catholic Church. A History, Minnesota 2009, p. 82.

${ }^{44}$ Patrick Gilli : Aux sources de l'espace politique. Techniques électorales et pratiques délibératives dans les cités italiennes (XII $-\mathrm{XIV}^{\mathrm{e}}$ siècles), in : L'espace public au Moyen Âge. Débats autour de Jürgen Habermas, éd. Patrick Boucheron/Nicolas Offenstadt, Paris 2011, p. 229-247. Au XII ${ }^{\mathrm{e}}$ siècle, dans le but de décourager l'ingérence par le biais de la pression sociale et d'assurer la fiabilité des résultats électoraux, les électeurs de Pistoia, une ville située au centre-ouest d'Italie, étaient tenus de prêter serment qu'ils «ne céderaient à aucun pouvoir en dehors de la ville, ne prendraient ni ne donneraient aucun pot-de-vin ou promesse, et ne feraient aucun serment ou accord, bref, ne feraient rien qui puisse entraver de quelque manière que ce soit leur action en tant qu'agents libres ». Cf. Sara L. UCKELMAN/Joel UCKELMAN : Strategy and Manipulation in Medieval Elections, p. 2, https://eprints.illc.uva.nl/401/1/PP-2010-22.text.pdf .

${ }^{45}$ Annales Placentini Guelfi. A. 1220-1223, in : MGH SS 18, éd. G. H. PERTZ, Stuttgart 1863, p. 438-439: Die Iovis, 10 kal. Aprilis, predictus potestas Cremone centum de militibus societatis militum ad civitatem accedere fecit, de quibus a societatis consulibus militum quatuor pro podestate comunis eligenda petivit, et totidem a popularibus. Qui consules dederunt ei [liste des noms] qui steterunt in camera communis pro potestate eligenda usque ad diem sabbati proximum, non comedentes nec bibentes. Qui cum illis, qui erant pro populo, accordari minime potuerunt. Qui cum illis, cum in electione potestatis se accordare cum popularibus non potuissent, die dominica sequenti predictus potestas Cremone precipit consulibus militum, ut darent ei 60 milites, et ex populo habuit totidem; de quibus militibus tres fuerunt electi ad brevia 
sortant fit approuver par cent chevaliers de la société des chevaliers de la ville et par cent populaires l'élection de huit consuls (quatre pour chaque entité). Ceux-ci furent enfermés dans une chambre commune jusqu'au samedi, sans manger ni boire pour désigner le nouveau podestat. L'échec de cette tentative incita le podestat sortant à réitérer la mesure en faisant sélectionner par soixante membres des deux partis, six nouveaux électeurs. Ils furent enfermés du dimanche au vendredi suivant, selon le même régime.

Les pouvoirs séculiers désireux d'accélérer l'élection du pape, le principe du conclave laïc a été introduit dans l'Église, mais en parfait accord chronologique avec les propositions des décrétistes comme Alanus Anglicus (†1210). Aux alentours de 1200, ce canoniste anglais pensait qu'il était important que le peuple de Rome contraigne, si nécessaire, les cardinaux à une décision électorale : «Que se passe-t-il si les deux parties ne parviennent pas à se mettre d'accord? Il s'agit de se réfugier dans les bras du pouvoir séculier [...], que les Romains viennent emprisonner les cardinaux et les obligent à prendre une décision commune $» .{ }^{47}$

La manière dont le premier ${ }^{48}$ conclave de l'histoire des élections papales s'est déroulé, cependant, ne correspond probablement pas aux

et totidem de popularibus, qui ea die in comunis camera fuerunt pro potestate eligenda inclusi. Hii tres pro militibus fuerunt, scilicet [liste des noms] qui steterunt cum popularibus in ipsa camera usque ad diem Veneris proximum [...] Ea vero die divina misericordia concorditer eligerunt in potestatem communis Placentie dominum Nigrinum Marianum. Cf. également GiLLI : Aux sources de l'espace politique, p. 242.

46 Titre donné au Moyen Âge au premier magistrat de certaines villes d'Italie et du midi de la France.

${ }^{47}$ Voir l'édition de la glose d'Alanus Anglicus au canon Licet, dans son Apparatus à la Compilatio I, glose tirée des ms. Vat. Lat. 1377 et Vat. Lat. 2509 : Quid ergo fiet si nullo modo due partes possunt consentire, recurratur ad brachium seculare [...], hoc modo quod veniant romani et includant cardinales in conclavi et compellant eos consentire. Cf. GILLI : Aux sources de l'espace politique, p. 243; Karl WENCK : Das erste Konklave der Papstgeschichte. Rom August bis Oktober 1241, Quellen und Forschungen aus italienischen Archiven und Bibliotheken 18 (1926), p. 101-170, ici : p. 106.

${ }^{48}$ L'information, souvent lue, que dès 1216 les citoyens de Pérouse avaient emprisonné les cardinaux par crainte d'un processus électoral long (et donc coûteux pour eux), remonte à un commentaire de la glose ordinaire (Glossa Ordinaria) de Bernhard de Parme (†1266) 
idées d'Alanus Anglicus. En 1241, en effet, le sénateur romain Matteo Orsini, qui organisait la défense de la ville de Rome contre l'empereur excommunié Frédéric II, a pris des mesures radicales pour forcer les cardinaux, après la mort de Grégoire IX, à élire rapidement un successeur. Une lettre des personnes concernées décrit la situation :

« Devons-nous oublier cela, écrivent les cardinaux, à quel point nous avons été traités avec indignité ? Comment nous avons été trainés au donjon électoral sur les mains et les pieds et honteusement battus comme des voleurs ? Comment un de nos frères a été arraché du sol par ses vénérables cheveux blancs et traîné sur la terre ... comme un voleur en route vers la potence ... ? Comment, sur le toit au-dessus de nos têtes, les gardes qui y étaient cantonnés ont-ils fait leurs besoins, qui ont dégouliné à travers les fissures et les crevasses sur le palier d'un de nos frères sous forme de boue puante et se sont répandus sur le lit d'un autre la nuit sous la pluie ? Comment un autre vénérable frère a été traîné de force à la morgue, alors qu'il était espionné et qu'on se moquait de lui, qu'on l'enterrait et qu'on le piquait cruellement par en dessous avec des arbalètes sur le brancard (en tissu) ? ». ${ }^{49}$

sur le Licet de vitanda. Cette glose est citée par Alanus Anglicus, avec la remarque suivante: «On dit que cela s'est produit lors de l'élection de Honoré III à Pérouse et pareillement après la mort de Grégoire IX» (ita dicitur factum fuisse in electione Honorii III apud Perusinum et idem fuit factum post mortem Gregorii IX). Un peu plus tard, le chapelain pontifical sous le pape Clément IV, Martin de Troppau ( $† 1279)$, fait également un rapport en conséquence, probablement en fonction de la Glossa Ordinaria. Cf. MARTIN DE TROPPAU : Chronicon Pontificum, p. 438,1.17. Il y a sans doute une rétroprojection des événements de 1265 (élection de Clément IV également à Pérouse) qui devraient être légitimés par des précédents. Pour l'ensemble, voir WENCK : Das erste Konklave, p. 109.

${ }^{49}$ Karl HAMPE : Ein ungedruckter Bericht über das Konklave von 1241 im römischen Septizonium (Heidelberger Akademie der Wissenschaften. Philosophisch-historische Klasse. Sitzungsberichte), Heidelberg 1913, p. 28 : Numquid obliti sumus, quam viliter tractati fuimus per manus et pedes ad carcerem et pulsati turpiter sicut fures? Nonne veneranda canicies fratris nostri contumeliose fuit de sacro vertice detractata, qui proiectus in terram, hurnero, capite et toto corpore deorsum prostratis, tam diu per pedes tractus velud latro ad suspendium et de ipsa gratia, dorso currente interdum per acutos lapides, est abstractus et delatus tandem per vias publicas in tapeto, unde incurrerit incurabilem corporis lesionem? Annon super testitudines nostris capitibus imminentes a custodibus decubantibus in eisdem urina sepius fundebatur, que per rimas et crepidines super unius fratris nostri cubiculum, velud olens locium, et de altera, ubi sua purgamenta sternebant, mixta imbribus super alterum noctibus delluebat, propter quod super stratum ad tantam arcendam iniuriam aptavit unus quorium, alter quasi tentorium, quasi exceptorium feditatis? Nonne venerabilis alter frater delatus violenter est in secreto mortuorum, super quem spuebant et lamentationum funebrium infausta carmina derisorie decantabant et percuciebant durius sub grabato cum arcubus balistarum? - Une 
Pendant 64 jours, du 22 août au 25 octobre 1241, le sénateur Matteo Orsini fit enfermer les treize cardinaux électeurs dans le Septizonium, une ruine d'un ancien palais de la Rome antique. En faisant verrouiller les portes avec la clé - cum clave $^{50}$ - dans cet endroit où le manque d'hygiène et la chaleur torride d'été étaient oppressants, un triple objectif était recherché. Non seulement le sénateur espérait ainsi presser les cardinaux tout en s'assurant que les électeurs ne soient pas influencés de l'extérieur, mais le conclave ecclésiastique visait également à imiter la réunion des apôtres à la Pentecôte et à attendre les conseils divins avant de voter.

Les cardinaux étaient en conclave depuis quatre bonnes semaines, lorsque le cardinal d'Angleterre Robert de Sumercote décédait le 26 septembre 1241. Malgré le temps écoulé, ils ne parvenaient pas à se mettre d'accord sur un digne successeur au pape Grégoire. La majorité des deux tiers n'a pas été atteinte lors des procédures de vote. Mais ce n'est que lorsque le sénateur Matteo Orsini menaça les cardinaux d'exhumer le corps du pape Grégoire IX et de le leur présenter en grande tenue qu'un candidat de compromis fut finalement accepté le 25 octobre 1241. Le plus ancien et le plus faible des cardinaux a été élu et se fit appeler Célestin IV. Il meurt, cependant, seize jours plus tard sans avoir été couronné pape. Un autre conclave s'imposait, donc. Or, les électeurs, à peine les élections terminées, avaient fui la ville de Rome. La lettre susmentionnée provient de ces cardinaux. Ils tentent de justifier auprès de ceux qui restent à Rome pourquoi ils refusent de revenir dans la ville pour une nouvelle élection papale. Une exagération des horreurs de ce conclave peut avoir été possible. La libre invention, cependant, ne peut guère exister, car cela aurait entaché le but de la lettre. Le conclave de 1241 est entré dans l'histoire de l'élection papale comme le « conclave des horreurs » (Schreckenskonklave dans l'historiographie allemande).

traduction allemande abrégée avec explication detaillée du contexte est disponible en ligne : http://www.vaticanhistory.de/kon/html/coelestin\%20iv_.html .

${ }^{50}$ Expression latine, cum clave signifie littéralement «avec clé » et désigne en latin classique une pièce «fermée à clef ». D'où le conclave qui est, pour l'Église catholique romaine jusqu'à nos jours, le lieu où sont enfermés les cardinaux rassemblés pour élire le pape. 
La procédure, qui a d'abord été imposée par les séculiers aux cardinaux et qui, peut-être pas par hasard, s'est à nouveau inspirée du modèle du monastère, a fait ses preuves dans les années suivantes. Elle a donc été rendue obligatoire. L'institutionnalisation du conclave épiscopal a été faite en 1274 par la bulle Ubi periculum de Grégoire X qui, lui, avait été élu après une sedisvacance excessivement prolongée de presque trois ans en 1271. Dans son cas, après un conclave d'un an, le magistrat de la ville de Viterbe avait réduit la nourriture des cardinaux au pain et à l'eau. Finalement, il enleva le toit du palais papal où ils étaient rassemblés. La bulle Ubi periculum réglemente donc de façon definitive l'élection pontificale. En substance, des conditions de vie simples (un seul domestique, une simple chambre à coucher) ainsi que des restrictions alimentaires (après 3 jours, seulement 2 repas par jour; à partir du huitième jour, seulement du pain, de l'eau et du vin) devaient inciter les cardinaux, en outre privés de leurs revenus pendant toute la durée de l'élection, à prendre une décision rapide. ${ }^{51}$ L'importance de ces mesures detaillées s'impose à l'esprit par une simple observation des élections dans les pays moins stables : la procédure de proclamation des votes dans les États africains pourrait certainement être considérablement accélérée si les membres des commissions électorales devaient se soumettre à des conditions similaires.

\subsection{Le mode d'élection ecclésiastique introduit dans l'Empire}

À l'image du modèle ecclésiastique, au XIII ${ }^{\mathrm{e}}$ siècle, il a été appliqué au choix du roi romain l'idée qu'une élection devait être tenue par un

${ }^{51}$ Ubi periculum, cap. 1 : Verum si, quod absit, infra tres dies postquam, ut praedicitur, conclave praedictum iidem cardinales intraverint, non fuerit ipsi ecclesiae de pastore provisum, per spatium quinque dierum immediate sequentium, singulis diebus tam in prandio quam in cena uno solo ferculo sint contenti. Quibus provisione non facta decursis, extunc tantummodo panis, vinum et aqua ministrentur eisdem, donec eadem provisio subsequatur. Provisionis quoque huiusmodi pendente negotio, dicti cardinales nihil de camera papae recipiant nec de aliis eidem ecclesiae tempore vacationis obvenientibus undecunque, sed ea omnia, ipsa vacatione durante, sub eius cuius fidei et diligentiae camera eadem est commissa, custodia maneant, per eum dispositioni futuri pontificis reservanda; cf. Josep M. COLOMER/Iain MCLEAN : Electing Popes, p. 1-22, ici : p. 12-14. 
organe séparé. Si l'unanimité ne pouvait être obtenue, ses membres pouvaient également voter à la majorité. ${ }^{52}$

Les textes juridiques créés depuis 1198 offrent suffisamment de points de référence, à cet égard: dans de nombreuses décisions d'Innocent III et de ses successeurs, il est question des «princes allemands qui ont le droit d'élire le roi ». Devrait-on y voir une preuve de l'idée que seul un certain groupe de princes avait le droit de vote? Il n'est pas évident que cette clause relative soit entendue de manière restrictive. Le contexte suggère plutôt qu'elle est utilisée de manière énonciative, c'est-à-dire « les princes allemands, qui, comme on le sait, ont le droit de vote ». En effet, le pape ne met pas en question le droit des princes d'élire, mais il examine la légitimité de la procédure et surtout l'idonéité des candidats. ${ }^{53}$

En effet, après la double élection de Philippe de Souabe et Otton IV en 1198, il se posait la question de savoir lequel des deux élections était légitime. Ayant longtemps hésité, le pape Innocent III intervenait finalement en prononçant ses réflexions (fin 1200/début 1201) dans un

${ }^{52}$ Armin Wolf : Die Entstehung des Kurfürstenkollegs 1198-1298. Zur 700-jährigen Wiederkehr der ersten Vereinigung der sieben Kurfürsten, Idstein 1998, présente d'une facon bien accessible les sources (latin avec traduction allemande). Pourtant, ses commentaires et même la datation des extraits de sources induisent souvent ses lecteurs en erreur, car il est convaincu d'une théorie invraisemblable et aberrante qu'il veut nécessairement prouver, même en redatant certaines sources qui ne correspondent pas à son schéma chronologique. Selon lui, au XIII ${ }^{\mathrm{e}}$ siècle, les princes décident de limiter le corps électoral à sept personnes, à savoir les trois archevêques rhénans plus le comte palatin du Rhin, le margrave de Brandebourg, le duc de Saxe et le roi de Bohême. Même si aucune source n'explique les raisons de leur choix, elles auraient eu, selon lui, comme base l'idée que seules les personnes habilitées à hériter du trône avaient le droit de voter aux élections royales. Dans ses nombreuses publications, Wolf essaie de prouver sa théorie par des analyses fondées sur une vaste base de données généalogiques qu'il a accumulées, mais qu'il n'a jamais rendues accessibles dans leur ensemble. Même si on accepte ses constructions généalogiques souvent spéculatives, il reste inimaginable que dans la société médiévale, les princes de l'Empire auraient pu savoir qui d'entre eux pouvait se réclamer le statut d'être dans sa génération le représentant principal d'un «königlicher Tochterstamm » (une ligne de descendance directe des rois ottoniens du $\mathrm{X}^{\mathrm{e}}$ siècle, compte tenu du principe que par défaut de fils les filles peuvent transmettre le droit d'héritage). Ce principe était facilement applicable pour une ou deux générations en arrière, mais impossible sur une période de trois siècles.

53 INNOCENT III : Innocentii III. decretalis, éd. Weiland, p. 506. 
discours devant les cardinaux, connu comme Deliberatio super tribus electis. Il reprenait le raisonnement de la Deliberatio dans la bulle Venerabilem fratrem nostrum relative à l'élection d'Otton IV comme roi des Romains (1202). Cette bulle faisait désormais parti du droit canonique et était considérée ainsi comme le modèle pour juger de la légitimité de toute élection royale. La bulle Venerabilem désigne les électeurs d'Otton comme « la plupart de ceux qui détiennent par droit et coutume le pouvoir d'élire le roi qui doit être promu empereur ». ${ }^{54}$

Le pape fait évidemment référence aux princes allemands, sans pourtant préciser d'avantage qui appartenait à ce groupe, bien qu'il eût un intérêt de le préciser pour renforcer son argument. Force est donc d'assumer qu'il n'y avait pas encore un groupe privilégié d'électeurs qui se prétendait ce droit à l'exclusion de tous les autres. Dans la Deliberatio, Innocent III parle des «princes à qui revient principalement l'élection de l'empereur» (principes, ad quos principaliter spectat imperatoris electio). ${ }^{55}$

Ici, le mot principaliter ne doit pas être interprété comme faisant référence à un tel cercle restreint et privilégié, mais il doit être entendu de façon littérale comme « d'abord » (principium désignant en latin le début et l'origine). En somme, ce sont d'abord les princes (donc les grands de l'Empire et plus précisément ceux du regnum theutonicum, donc l'Empire au nord des Alpes) qui ont le droit de faire l'élection. Pourtant, s'ils ne procèdent pas assez vite ou le font de façon douteuse, la décision du choix revient alors au pape. Dans la Deliberatio, au sujet de l'élection disputée d'Otton IV, le pape Innocent III soulignait ainsi qu'« on aurait dû déjà longtemps avoir eu recours au siège apostolique, à qui cette cause appartient évidement à cause de son origine et sa fin. ». ${ }^{56}$

${ }^{54}$ INNOCENT III : Innocentii III. decretalis, éd. Weiland, p. 506 : plures ex illis qui eligendi regem in imperatorem promovendum de iure ac consuetudine obtinent postestatem.

${ }^{55}$ INNOCENT III : Deliberatio, éd. Kempf, p. 88.

${ }^{56}$ INNOCENT III : Deliberatio, éd. Kempf, p. 52 : Ad apost. sedem iam pridem fuerat reccurendum, ad quam negotium istud principaliter et finaliler dignoscitur pertinere. 


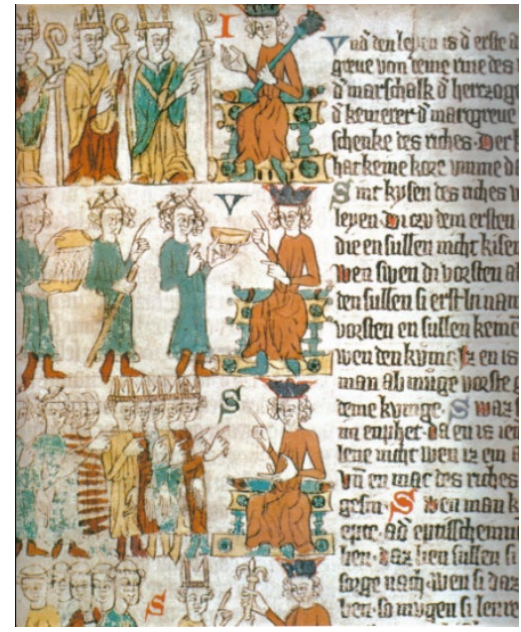

Fig. 2 : L'élection du roi des Romains. Sachsenspiegel de Heidelberg, vers 1300.

Source : Collections historiques digitalisées de la bibliothèque universitaire de Heidelberg, Cod. Pal. germ. 164, f. 21 r.

En haut : les princes-évêques, lors de l'élection, désignent le roi en le montrant du doigt. Au milieu : les princes laïcs reconnaissables aux objets qu'ils tiennent dans leurs mains : le comte palatin du Rhin a préséance en tant que sénéchal du royaume. Il remet au roi un bol de nourriture en or. Derrière lui se trouve le duc de Saxe, reconnu comme le maréchal de Saxe grâce à son bâton de maréchal tenu dans sa main droite. Le troisième est le chambellan, le margrave de Brandebourg, qui verse une boisson chaude d'une grande coupe dans un petit récipient.

En bas : le nouveau roi devant les grands seigneurs de l'Empire. La représentation des attributs correspond à l'illustration de la Bulle d'or de 1356.

Dans la première moitié du XIII ${ }^{\mathrm{e}}$ siècle, le Miroir des Saxons, le Sachsenspiegel, ${ }^{57}$ le plus ancien coutumier allemand, ne contient pas non plus de preuve d'un cercle électoral délimité. Il indique qu'à l'exception du roi de Bohême les sept princes, qu'on appellera à partir du XIV

${ }^{57}$ Écrit entre 1220 et 1235 en moyen bas allemand, le Sachsenspiegel n'est pas un code de lois, mais un livre juridique (Rechtsbuch). Il s'agit d'un traité d'un seul juriste allemand, Eike de Repgow (1180-1233). Il explique la loi coutumière telle qu'il l'entend et gagne en autorité uniquement à cause de l'appréciation de son texte par les autres spécialistes du droit. 
siècle les princes électeurs, «devraient d'abord élire avec son nom » $(z u$ allererst mit Namen kiesen sollen ${ }^{58}$ ) le roi à désigner.

Il est très clair, cependant, et même stipulé formellement que les electeurs ne doivent nommer que celui que l'ensemble des princes a choisi d'un commun accord. Les électeurs n'ont pas le droit de choisir le roi, mais seulement le privilège de l'élire (= nominer) formellement en prémiers. En clair, les princes se mettent d'accord dans une procédure informelle, dont la fonction probablement ne differait pas fondementalement $\mathrm{du}$ palabre du village africain, sur la personne à désigner comme roi, puis, l'un après l'autre et par ordre de préséance (et donc les six électeurs privilégiés d'abord), ils prononcent formellement le résultat et l'acceptent pour soi. Ce n'est pas la procédure électorale qui est réglementée ici, mais la question d'ordre dans le rang. Dans ce sens, l'exclusion du roi de Bohême dans le Miroir des Saxons est compréhensible : le duc de Bohème qui était le voisin et donc le concurrent direct du duc des Saxons aurait profité de sa participation à l'élection pour démontrer sa préséance. Sa dignité royale tout récemment obtenue lui aurait donné le premier rang parmi les électeurs séculiers, renvoyant ainsi le duc de Saxe au troisième rang. ${ }^{59}$

C'est peu avant l'élection de Rodolphe I en 1273 que l'idée d'un corps électoral d'électeurs habilités à élire le roi émerge. ${ }^{60}$ Mais elle est

${ }^{58}$ EIKE DE REPGOW : Sachsenspiegel, éd. Ruth Schmidt-Wiegand, p. 259. Voir également Aloys MEISTER : Deutsche Verfassungsgeschichte von den Anfängen bis ins 15. Jahrhundert, Paderborn 2015, note 2, p. 117-118, citant Sachsenspiegel III, 57, 2.

${ }^{59}$ En raison de la rivalité avec le pape, la vacance du trône impérial dure depuis 1250 . En 1273 , les électeurs sont soucieux de ne pas porter au pouvoir un prince trop puissant afin de préserver leurs propres prérogatives et d'éviter tout risque de transmission héréditaire de la couronne. Aussi, écartent-ils le roi de Bohême, Ottokar II, lui aussi candidat, et élisent son rival, le modeste comte souabe Rodolphe de Habsbourg. Ottokar II était le petit-fils de Phiippe de Souabe, roi de Germanie de 1198 à 1208. Cf. Volker Joachim WALLERANG : Die Wahl Rudolfs von Habsburg zum römisch-deutschen König im Jahr 1273, Munich 2004; Heike SCHWAB : Die Wahl Rudolfs von Habsburg 1273 zum König des Deutschen Reiches, Pfälzer Heimat 45 (1994), p. 67-74.

${ }^{60}$ Sur les théories au sujet de l'origine du collège électoral, voir Thomas ERTL: Alte Thesen und neue Theorien zur Entstehung des Kurfürstenkollegiums, Zeitschrift für Historische Forschung, 30/4 (2003), p. 619-642, ici : p. 634-635; Franz-Reiner ERKENS : 
clairement définie, pour la première fois, par Martin de Troppau dans sa chronique papale et impériale rédigée en 1268/71. Henri II avait organisé l'élection du roi de telle manière qu'elle devait être effectuée par les titulaires des fonctions de la cour, notamment les archevêques de Mayence, Cologne et Trèves en leur qualité de chanceliers d'Allemagne, d'Italie et de Bourgogne; le margrave de Brandebourg en tant que chambellan d'Empire; le comte palatin du Rhin en tant que sénéchal; le duc de Saxe en tant que porteur de l'épée; le roi de Bohême en tant qu'échanson d'Empire. «Ils nomment le plus haut seigneur du monde pour tous » (Hii statuunt dominum cunctis per secula summum). ${ }^{61}$

Selon Martin de Troppau, le droit de vote a été transféré aux électeurs après la mort d'Otton III décédé sans enfant en 1002, ce qui est évidement une légende ayant pour but de légitimer un processus de réduction de l'élection à un cercle restreint et bien défini d'électeurs. À la fin des années 1220, l'idée était déjà présente dans le Sachsenspiegel. Mais c'est seulement dans les années 1270 que les électeurs privilégiés ont eux-mêmes repris cette légitimation supplémentaire de leur fonction électorale exclusive et l'ont inscrite comme faisant partie désormais de leurs attributions. Si les adaptations du Sachsenspiegel en Allemagne du sud, créées à la fin du XIII ${ }^{\mathrm{e}}$ siècle, font mention de cette évolution, elles ne précisent cependant plus cette obligation de lier les électeurs privilégiés à la décision électorale de tous les princes, qui précède la leur.

Devant la volonté du pape Jean XXII de reconnaitre Louis IV de Bavière comme roi des Romains, malgré son élection par la majorité des princes électeurs, ceux-ci rédigèrent à Rhens une loi électorale en 1338 dans laquelle ils affirmèrent que seul le collège électoral était apte à élire le roi, automatiquement élevé empereur d'Occident. Ce texte devint, à la diète de Francfort, le code Licet juri promulgué devant les princes, mais aussi les représentants des villes, de la petite et de la moyenne noblesse.

Soucieux de légitimer son avènement contesté comme candidat du pape qui devait remplacer Louis «le Bavarois», Charles IV de

Kurfürsten und Königswahl. Zu neuen Theorien über den Königswahlparagraphen und die Entstehung des Kurfürstenkollegiums (MGH-Studien und Texte 30), Hannover 2002.

${ }^{61}$ Martin de Troppau : Chronicon Pontificum, p. 466, 1. 24. 
Luxembourg compléta ce document par lequel le groupe d'électeurs est finalement devenu un collège dans le livre juridique impérial, connu sous le nom de Bulle d'or (Goldene Bulle) de 1356. Désormais reconnue comme la loi fondamentale du Saint-Empire romain, la Bulle d'or de Charles IV réglementait les modalités de l'élection et du couronnement des rois et empereurs romains. Elle garantissait à l'Empire un processus de décision réglant les moindres details de procédure, voire de cérémonie et évitait ainsi au maximum tout contentieux de rang entre les électeurs. Toute chose qui aurait pu provoquer des conflits dans la situation de transition extrêmement fragile, surtout lorsqu'il manquait de roi capable de résoudre une telle question par sa décision. ${ }^{62} \mathrm{La}$ formule «le roi des Romains qui doit être promu empereur» (rex romanorum in imperatorem promovendus), issue de la décrétale Per Venerabilem du pape Innocent III en 1202, se trouvait ainsi renforcée dans l'Empire. ${ }^{63}$

Non seulement les droits et devoirs des électeurs, lors de l'élection royale, y ont été renforcés, mais aussi l'élection du roi des Romains est formellement détachée de l'approbation du pape. Il n'avait plus d'arbitrages à prononcer. L'innovation majeure de la Goldene Bulle était que, pour la première fois, le roi pouvait être élu par les votes de la majorité et ne dépendait pas du consentement de tous les princes électeurs dans leur ensemble. Mais pour parvenir à pareil résultat, il a fallu faire croire que la minorité s'était abstenue de voter et qu'en fin de compte tous étaient d'accord. ${ }^{64}$ Cependant, pour des raisons déjà évoquées, même la Bulle d'or ne s'intéresse pas en premier lieu aux

62 Ernst SCHUBERT : Königswahl und Königtum im spätmittelalterlichen Reich, in : Zeitschrift für Historische Forschung 4 (1977), p. 285-290, ici : p. 262; Bernd-Ulrich HERGEMÖLLER: Art. «Goldene Bulle, 1356 », in: Historisches Lexikon Bayerns, https://www.historisches-lexikon-bayerns.de/Lexikon/Goldene_Bulle,_1356;Armin WolF: Art. « Kurfürsten », in: Historisches Lexikon Bayerns, https://www.historisches-lexikonbayerns.de/Lexikon/Kurf\%C3\%BCrsten; Francis RAPP: Les Relations entre le Saint-Empire et la papauté, d'Otton le Grand à Charles IV de Luxembourg (962-1356), https://www.clio.fr/BIBLIOTHEQUE/les_relations_entre_le_saint_empire_et_la_papaute _dotton_le_grand_a_charles_iv_de_luxembourg_962_1356.asp .

${ }^{63}$ INNOCENT III : Innocentii III. decretalis, éd. Weiland, p. 505.

${ }^{64}$ SCHUBERT : Königswahl, p. 257-338. 
procédures de vote et de décision. Plus d'un tiers du texte traite exclusivement des questions de cérémonie et de préséance. ${ }^{65}$

Ce choix germanique du principe de la royauté électif et les conflits nés des élections impériales expliquent le regard des sources françaises sur les élections doubles dans la première moitié du XIV ${ }^{\mathrm{e}}$ siècle. La compétition pour la couronne était de l'ordre de l'impensable en France, déjà vers 1300 , alors qu'au XIV ${ }^{\mathrm{e}}$ siècle, les élections impériales étaient réévaluées au moment où s'imposait dans le royaume de France un véritable choix dynastique, celui de Philippe de Valois. ${ }^{66}$

\section{Conclusion}

Les modalités d'accession au pouvoir, aussi bien dans les institutions ecclésiastiques que dans le contexte laïc, ne correspondaient guère à l'idée que l'on se fait d'une élection aujourd'hui. Non seulement l'avantage numérique d'un candidat n'était pas une exigence absolue, mais également la question de savoir qui avait le droit de voter ou qui ne l'avait pas n'avait aucun sens à une période où l'élection était perçue comme une acclamation. Certes, le principe était que la majorité l'emportait, mais en réalité, le souci d'unanimité dominait dans la procédure de l'époque. Les élections abbatiales, épiscopales et pontificales ainsi que celles dans l'Empire étaient ainsi réglées.

${ }^{65}$ Les votes sont exprimés, en effet, par les trois archevêques et quatre laïcs en fonction du rang et dans l'ordre suivant: l'archevêque de Trèves comme chancelier de Bourgogne incorporée au Saint-Empire romain germanique à partir de 1032; l'archevêque de Cologne comme chancelier de l'Italie impériale; le roi de Bohême en tant que prince laïc couronné; le comte du Palatinat près du Rhin en tant que sénéchal et régent impérial des pays franconiens; le duc de Saxe comme grand maréchal et administrateur de l'Empire dans tous les pays où la loi saxonne s'applique; le Margrave de Brandebourg en tant que chambellan d'Empire; l'archevêque de Mayence avait le rang le plus élevé en tant qu'archichancelier des États fédéraux allemands et a été le dernier à voter en raison de la possibilité d'un vote prépondérant.

${ }^{66}$ Gilles LECUPPRE : Ordre capétien et confusion germanique. La compétition royale dans les sources françaises au XIII ${ }^{\mathrm{e}}$ siècle, in : Convaincre et persuader. Communication et propagande aux XII ${ }^{\mathrm{e}}$ et XIII ${ }^{\mathrm{e}}$ siècles, éd. Martin Aurell, Poitiers 2007, p. 513-531; Gilles LECUPPRE: Schisme impérial, schisme pontifical, Cahiers de recherches médiévales et humanistes 20 (2010), p. 145-161. 
Cette préoccupation peut sembler étrange à un observateur du XXI siècle. La fiction légale qui semble aller de soi dans les démocraties occidentales aujourd'hui veut que la majorité d'une assemblée ou d'un peuple décide au nom de tous et que la minorité respecte le résultat du scrutin. Il suffit pourtant de regarder les événements autours des élections dans les pays moins stables pour comprendre que le vote de la majorité seule ne suffit pas pour établir la paix.

$\mathrm{Au}$ Moyen Âge, la légitimité d'une élection, tant dans le contexte ecclésiastique que dans le contexte séculier, ne résidait pas tant dans le processus électoral utilisé que dans l'autorité divine. Autrement dit, l'objectif n'était pas d'avoir une élection soumise à une règle particulière, mais une élection devant refléter la volonté de Dieu, révélée par le consensus. Le motif du bon chrétien qui ne doit pas aspirer à un rang plus élevé, mais qui doit attendre d'y être contraint, exprimait et symbolisait les principes de la royauté héréditaire et élective au Moyen Âge. En ce sens, l'unanimité, l'acclamation, l'humilité et même la contraignance participent $\mathrm{du}$ rituel du consensus électoral. 


\title{
Références bibliographiques
}

\author{
Abbreviations \\ MGH Monumenta Germaniae Historica \\ SS Scriptores in folio \\ Const. Constitutiones et acta publica imperatorum et regum
}

Les textes du Moyen Âge allemand sont pour la plupart cités d'apres leur édition du XIXe siècle dans les séries MGH SS et MGH Const., car celles-ci sont les plus accessibles en ligne dans le monde francophone. Ils ont été verifiés en comparant les éditions les plus récentes qui peuvent être identifiés à travers le site "Geschichtsquellen des deutschen Mittelalters » de l'Académie bavaroise des sciences (www.geschichtsquellen.de).

\section{Sources}

Annales Placentini Guelfi. A. 1220-1223, in : MGH SS 18, éd. G. H. Pertz, Stuttgart 1863, p. 438-439.

en ligne : https://www.dmgh.de/mgh_ss_18/index.htm\#page/403/mode/1up .

The Chronicles of Rome. An Edition of the Middle English Chronicle of Popes and Emperors and The Lollard Chronicle, éd. Dan Embree, Woodbridge 1999.

Cluny : Les plus anciens documents originaux de l'abbaye de Cluny, éd. Hartmut Atsma/S. Barret/Jean Vezin (Monumenta Palaeographica Medii Aevi. Series Gallica I.4), Paris 1997.

The First Crusade, The Accounts of Eye-Witnesses and Participants, éd. August C. Krey, Princeton 1921.

ÉGINHARD : Vie de Charlemagne, éd. et trad. Louis Halphen, Paris 1923.

EIKE DE REPGOW: Sachsenspiegel des Eike von Repgow. Die Wolffenbütteler Bilderhandschrift. Cod. Guelf. 3.1 Aug. 20 ${ }^{0}$, ed. Ruth Schmidt-Wiegand, Berlin 2018.

FulCher DE ChARTRES: The First Crusade. The Chronicle of Fulcher of Chartres and Other Source Materials, éd. Edward M. Peters, Philadelphia 1998.

INNOCENT III : Innocentii III. Decretalis de iure pontificis in electione regis, in : MGH Const., éd. Ludwig Weiland, Hanovre 1896, vol. 2, $\mathrm{n}^{\circ}$ 398, p. 505-507 en ligne : https://www.dmgh.de/mgh_const_2/index.htm\#page/505/mode/1up .

INNONCENT III : Deliberatio domini papae super facto imperii de tribus electis, in: Regestum Innocentii III papae super negotio Romani imperii, éd. Friedrich Kempf (Miscellanea Historiae Pontificiae), Rome 1947, vol. 12, p. 75-91.

MARTIN DE TROPPAU : Chronicon pontificum et imperatorum, éd. Ludwig Weiland, in : MGH SS 22, éd. Georg Heinrich Pertz, Hanovre 1856, p. 377-475

en ligne : https://www.dmgh.de/mgh_ss_22/index.htm\#page/377/mode/1up .

Narratio de electione Lotharii, in : MGH SS 12, éd. G. H. Pertz, Hanovre 1856, p. 509-512 en ligne : https://www.dmgh.de/mgh_ss_12/index.htm\#page/509/mode/1up .

ORDERIC ViTALIS : The Ecclesiastical History of Orderic Vitalis, vol. 6, livre 13, éd. et trad. Marjorie Chibnall, Oxford 1978. 
Ordonnances des rois de France de la troisième race. Sixième volume contenant les ordonnances de Charles V, éd. Denis-François Secousse, Paris 1741 en ligne : https://gallica.bnf.fr/ark:/12148/bpt6k118974b.image .

OTTON DE FREISING : Ottonis et Rahewini gesta Friderici I. imperatoris, Hanovre 1912 en ligne : https://www.dmgh.de/mgh_ss_rer_germ_46/index.htm\#page/(III)/mode/1up .

ThietMAR VON MERseburg: Chronik, retranscrite et expliquée par Werner Trillmich (Ausgewählte Quellen zur deutschen Geschichte des Mittelalters, Freiherr vom SteinGedächtnisausgabe 9), Darmstadt 2011.

Ubi periculum, la bulle de Grégoire X en 1274, disposition: < Della elezione e della potestà dell'eletto > en ligne : http://www.intratext.com/IXT/ITA0136/_P5.HTM, para. 6 .

\section{Études}

AUTRAND, Françoise : La succession à la couronne de France et les ordonnances de 1374, in : Représentation, pouvoir et royauté à la fin du Moyen Âge, éd. Joël Blanchard, Paris 1995, p. 25-32.

BAECHLER, Gerhard/CAMENZIND, Erich (éd.) : Kirchenpatrone Deutschfreiburgs, Freiburg 1989.

BASDEVANT-GAUDEMET, Brigitte : Quelques réflexions sur la < Libertas Ecclesiae > dans les procédures de désignations épiscopales au cours des siècles, Revue historique de droit français et étranger 94/1 (2016), p. 13-25.

BAUMGARTNER, Frederic J.: Behind Locked Doors. A History of the Papal Elections, Londres 2003.

Bindemann, Carl : Saint Augustin, Revue de théologie et de philosophie et compte-rendu des principales publications scientifiques 9 (1876), p. 414-444.

BoAs, George : Art. «Vox populi », in : Dictionary of the History of Ideas, éd. Philip Paul Wiener, New York 1973-1974, vol. 4, p. 497-500.

Boureau, Alain: Art. « Vox populi, vox Dei», in: Dictionnaire du vote, éd. P. Perrineau/D. Reynié, Paris 2001, p. 965-967.

BOUREAU, Alain : L'adage vox populi, vox Dei et l'invention de la nation anglaise $\left(\mathrm{VIII}^{\mathrm{e}}\right.$ XII ${ }^{\mathrm{e}}$ siècle), Annales. Économies, Sociétés, Civilisations 1992, p. 1071-1089.

Brosius, Christiane/Michaels, Axel/Schrode, Paula Ritual und Ritualdynamik. Schlüsselbegriffe, Theorien, Diskussionen, Göttingen 2013.

BÜTTNER, Andreas : Königsherrschaft im Mittelalter (Seminar Geschichte), Berlin/Boston 2018.

CANNING, Joseph : A History of Medieval Political Thought, 300-1450, Londres/New York 1996.

Chaplais, Pierre: English Medieval Diplomatic Practice, vol. 1: Documents and Interpretation, Londres 1982.

Clark, Linda/CARpenter, Christine (éd.) : The Fifteenth Century, vol. 4 : Political Culture in Late Medieval Britain, Woodbridge 2004.

Colomer, Josep M./McLean, Iain: Electing Popes. Approval Balloting and qualifiedmajority Rule, The Journal of Interdisciplinary History 29.1 (1998), p. 1-22. 
VAN EICKELS, Klaus : Otto IV. und Philipp von Schwaben, in : Die deutschen Herrscher des Mittelalters, éd. Bernd Schneidmüller/Stefan Weinfurter, Munich 2003, p. 272-292.

VAN EICKELS, Klaus: Vom inszenierten Konsens zum systematisierten Konflikt. Die englisch-französischen Beziehungen und ihre Wahrnehmung an der Wende vom Hochzum Spätmittelalter, Stuttgart 2002.

ERKENS, Franz-Reiner: Kurfürsten und Königswahl. $\mathrm{Zu}$ neuen Theorien über den Königswahlparagraphen und die Entstehung des Kurfürstenkollegiums (MGH-Studien und Texte 30), Hannover 2002.

ERTL, Thomas: Alte Thesen und neue Theorien zur Entstehung des Kurfürstenkollegiums, Zeitschrift für Historische Forschung, 30.4 (2003), p. 619-642.

FENICHEL, Hanna : The Concept of Representation, Berkeley 1972.

GAudemet, Jean: Les élections dans l'Église latine. Des origines au XVI ${ }^{\mathrm{e}}$ siècle, Paris 1979.

GILLI, Patrick: Aux sources de l'espace politique. Techniques électorales et pratiques délibératives dans les cités italiennes (XII ${ }^{\mathrm{e}}-\mathrm{XIV}^{\mathrm{e}}$ siècles), in : L'espace public au Moyen Âge. Débats autour de Jürgen Habermas, éd. Patrick Boucheron/Nicolas Offenstadt, Paris 2011, p. 229-247.

HAMPE, Karl: Ein ungedruckter Bericht über das Konklave von 1241 im römischen Septizonium (Heidelberger Akademie der Wissenschaften. Philosophisch-historische Klasse. Sitzungsberichte), Heidelberg 1913.

HANNIG, Jürgen: Consensus fidelium. Frühfeudale Interpretationen des Verhältnisses von Königtum und Adel am Beispiel des Frankenreiches, Stuttgart 1982.

HASsO, Hofmann : Repräsentation. Studien zur Wort- und Begriffsgeschichte von der Antike bis ins 19. Jahrhundert, Berlin 2003.

HERGEMÖLLER, Bernd-Ulrich: Art. «Goldene Bulle, 1356 », in: Historisches Lexikon Bayerns, https://www.historisches-lexikon-bayerns.de/Lexikon/Goldene_Bulle,_1356 .

HERMET, Guy: Les sources chrétiennes de la démocratie. La liberté par mégarde, Paris 2020.

DE CHERRIER, Claude Joseph : Histoire de la lutte des papes et des empereurs de la Maison de Souabe, de ses causes et de ses effets, vol. 2, Paris 1844.

JUlEROT, V. : < Y a ung grant désordre >. Élections épiscopales et schismes diocésains en France sous Charles VIII, Paris 2006.

KELLER, Hagen : Grundlagen ottonischer Königsherrschaft, in : Reich und Kirche vor dem Investiturstreit. Vorträge beim wissenschaftlichen Kolloquium aus Anlass des achtzigsten Geburtstags von Gerd Tellenbach, éd. Gerd Tellenbach/Karl Schmid, Sigmaringen 1985, p. 17-34.

KeLly, Joseph F. : The Ecumenical Councils of the Catholic Church. A History, Minnesota 2009.

KEMPF, Friedrich: Innocenz III. und der deutsche Thronstreit, Archivum Historiae Pontificiae 23 (1985), p. 63-91.

Koopmans, Jelle: À l'ombre de Pharamond. La royauté élective, Cahiers de recherches médiévales et humanistes 20 (2010), p. 135-143.

Le règlement des conflits au Moyen Âge. Actes du XXXI ${ }^{e}$ Congrès de la SHMESP, Paris 2001

en ligne : https://www.persee.fr/issue/shmes_1261-9078_2001_act_31_1 . 
LECUPPRE, Gilles : Schisme impérial, schisme pontifical, Cahiers de recherches médiévales et humanistes 20 (2010), p. 145-161.

LECUPPRE, Gilles : Ordre capétien et confusion germanique. La compétition royale dans les sources françaises au XIII ${ }^{\mathrm{e}}$ siècle, in : Convaincre et persuader. Communication et propagande aux XII ${ }^{\mathrm{e}}$ et XIII ${ }^{\mathrm{e}}$ siècles, éd. Martin Aurell, Poitiers 2007, p. 513-531.

LEMARIGNIER, Jean-François : La France médiévale. Institutions et sociétés, Paris 1970.

MANIN, Bernard : Principes du gouvernement représentatif, Paris 1995.

MeISTER, Aloys: Deutsche Verfassungsgeschichte von den Anfängen bis ins 15. Jahrhundert, Paderborn 2015.

Moulin, Léo: Sanior et maior pars. Note sur l'évolution des techniques électorales dans les Ordres religieux du $\mathrm{VI}^{\mathrm{e}}$ au XIII ${ }^{\mathrm{e}}$ siècle, Revue historique de droit français et étranger, Quatrième série 35 (1958), p. 491-529.

NonN, Ulrich : Geblütsrecht, Wahlrecht, Königswahl. Die Wahl Lothars von Supplinburg 1125, Geschichte in Wissenschaft und Unterricht 44 (1993), p. 146-157.

OSAWA, Takeo: Das Bischofseinsetzungsverfahren bei Cyprian. Historische Untersuchungen $\mathrm{zu}$ den Begriffen iudicium, suffragium, testimonium, consensus (Europäische Hochschulschriften XXIII.178), Francfort/Bern 1983.

Papal elections of the $11^{\text {th }}$ Century (1061-1099), en ligne: http://cardinals.fiu.edu/conclave-xi.htm .

PÉNÉAU, Corinne: Pour une histoire des élections médiévales et modernes, Cahiers de recherches médiévales et humanistes 20 (2010), p. 127-133.

PÉNÉAU, Corinne : Élections et pouvoirs politiques du VII ${ }^{\mathrm{e}}$ au XVII ${ }^{\mathrm{e}}$ siècle, Bordeaux 2008.

Pennington, Kenneth: The Golden Age of Episcopal Elections 1100-1300, Bulletin of Medieval Canon Law 35 (2018), p. 243-253.

Pennington, Kenneth : Decretal Letters of Pope Innocent III touching on Church and State, en ligne:

http://legalhistorysources.com/ChurchHistory220/Lecture\%20Four/InnocentIIIChurch State.html .

Podlech, Adalbert: La représentation. Une histoire du concept, Trivium 16 (2014), https://journals.openedition.org/trivium/4781 .

PoDlech, Adalbert: Repräsentation, in: Geschichtliche Grundbegriffe. Historisches Lexikon zur politisch-sozialen Sprache in Deutschland, éd. Otto Brunner/Werner Conze/ Reinhart Koselleck, vol. 5, Stuttgart 1972, p. 509-547.

POTTER, David L. : Politics and Faction at the French Court from the Late Middle Ages to the Renaissance. The Development of a Political Culture, en ligne : http://cour-de-france.fr/article1883.html .

RAPP, Francis: Les Relations entre le Saint-Empire et la papauté, d'Otton le Grand à Charles IV de Luxembourg (962-1356), en ligne :

https://www.clio.fr/BIBLIOTHEQUE/les_relations_entre_le_saint_empire_et_la_papau te_dotton_le_grand_a_charles_iev_de_luxembourg_962_1356.asp .

RIALS, Stéphane (éd.) : Le Miracle capétien, Paris 1987.

RoGGE, Jörg: Die deutschen Könige im Mittelalter. Wahl und Krönung (Geschichte kompakt), Darmstadt 2006.

SCHNEIDER, Reinhard/ZimmERMANN, Harald (éd.): Wahlen und Wählen im Mittelalter (Vorträge und Forschungen 37), Sigmaringen 1990. 
SCHNEIDMÜLLER, Bernd : Konsensuale Herrschaft. Ein Essay über Formen und Konzepte politischer Ordnung im Mittelalter, in : Reich, Regionen und Europa in Mittelalter und Neuzeit. Festschrift für Peter Moraw, éd. Paul-Joachim Heinig, Berlin 2000, p. 53-87.

SCHUBERT, Ernst : Königswahl und Königtum im spätmittelalterlichen Reich, Zeitschrift für Historische Forschung 4 (1977), p. 257-338.

SCHWAB, Heike: Die Wahl Rudolfs von Habsburg 1273 zum König des Deutschen Reiches, in : Pfälzer Heimat 45 (1994), p. 67-74.

STOLLBERG-RILINGER Barbara : Rituale, Francfort/New York 2013.

StOllberg-Rilinger, Barbara/NeU, Tim/Brauner, Christina (éd.) : Alles nur symbolisch? Bilanz und Perspektiven der Erforschung symbolischer Kommunikation, Cologne 2013.

UCKelman, Sara L./UCKelman, Joel : Strategy and Manipulation in Medieval Elections, en ligne : https://eprints.illc.uva.nl/401/1/PP-2010-22.text.pdf .

WALLERANG, Volker Joachim : Die Wahl Rudolfs von Habsburg zum römisch-deutschen König im Jahr 1273, Munich 2004.

WeILER, Bjön: The Rex renitens and the Medieval Ideal of Kingship, ca. 900-ca. 1250, Viator 31 (2000), p. 1-42.

VAN WiJNENDAELE, Jacques: Silences et mensonges autour d'un concile. Le concile de Sutri (1046) en son temps, Revue belge de philologie et d'histoire 83.2 (2005), p. 315353.

WENCK, Karl : Das erste Konklave der Papstgeschichte. Rom August bis Oktober 1241, Quellen und Forschungen aus italienischen Archiven und Bibliotheken 18 (1926), p. 101-170.

Wolf, Armin: Die Entstehung des Kurfürstenkollegs 1198-1298. Zur 700-jährigen Wiederkehr der ersten Vereinigung der sieben Kurfürsten, Idstein 1998.

WolF, Armin : Art. < Kurfursten >, in : Historisches Lexikon Bayerns, en ligne : https://www.historisches-lexikon-bayerns.de/Lexikon/Kurf\%C3\%BCrsten .

\section{Liste des illustrations}

Fig. 1: Avis aus Roys:

http://ica.themorgan.org/manuscript/page/77/112420

Fig. 2 : Sachsenspiegel de Heidelberg

https://digi.ub.uni-heidelberg.de/diglit/cpg164/0055/image 